\title{
Cervantes, fray Juan Gil y los mercaderes valencianos
}

\author{
JESÚs ViLLALMANZO*
}

\begin{abstract}
Resumen
En el artículo se dan a conocer varios documentos inéditos referentes a Cervantes, Fray Juan Gil y a varios mercaderes amigos de ambos personajes. Están fechados principalmente en los años 1580-1592, época de los viajes redentores a Argel del padre Gil e inmediatos sucesores, fecha también de la liberación de Cervantes y de su posterior estancia en Valencia. Especial interés tienen los documentos relativos a los contratos de fletamento de las naves redentoras. Digno de destacar es la sorprendente intervención de Cervantes, ofreciendo información de primera mano sobre un cautivo de Argel. Los que recibieron esta información, unos mercaderes sin escrúpulos, urdieron unas fraudulentas apuestas, donde se jugaron altas cantidades de dinero, en las que se vieron implicados varios centenares de personas acaudaladas, como mercaderes y maestros artesanos. Se apostaba sobre la vida o muerte de un pescador del Grao al que se daba por muerto, víctima de unos supuestos criminales que se hallaban detenidos en las cárceles de Valencia.
\end{abstract}

Palabras clave: Miguel de Cervantes Saavedra; Fray Juan Gil; Cautivos de Argel; Contratos de fletamento; Apuestas.

Title: Cervantes, frey Juan Gil and the Valencian merchants

\begin{abstract}
This paper brings to public knowledge various unpublished documents related to Cervantes, Father Juan Gil and several merchants that were friends of both. They are dated mainly in the years from 1580 to 1592, the time of the rescue voyages to Algiers of Father Gil and his immediate successors, and also the time of the rescue of Cervantes and his stay in Valencia after it. The documents related to the charter contracts of the rescue vessels have
\end{abstract}

* Archivo del Reino de Valencia. Investigador. jevica@telefonica.net 
special interest. It is also worth mentioning the surprising intervention of Cervantes offering first-hand information about a captive in Algiers. The receivers of this information, a few unscrupulous merchants, devised one fraudulent bet that involved a few hundreds of wealthy people (like merchants and master-craftsmen) risking huge sums of money. The bet was on whether or not a fisherman from El Grao was alive. This fisherman, reportedly dead, had seemingly fallen prey to several alleged criminals that were behind bars in Valencia.

Key Words: Miguel de Cervantes Saavedra; Father Juan Gil; Algiers captives; Charter contracts; Bets.

El motivo de volver de nuevo sobre personajes tan conocidos como Miguel de Cervantes y fray Juan Gil se debe a los nuevos hallazgos documentales referentes a estos dos insignes personajes históricos que nos han brindado los archivos valencianos. Cronológicamente se circunscriben a los años de 1580-1592 en los que dicho padre trinitario y sucesores comandaron los viajes oficiales de redención de cautivos en Argel y Cervantes consiguió su libertad. Las novedades cervantinas que aportamos se refieren a acontecimientos que ocurrieron a nuestro escritor durante su estancia de un mes largo de duración en la ciudad del Turia a su vuelta de Argel, sobresaliendo la implicación que tuvo, sin él saberlo, en una famosa apuesta, donde se jugaron elevadas sumas de dinero, y cuyos protagonistas fueron un cautivo al que se daba por muerto y la información que aportó ingenuamente Cervantes a unos comerciantes mallorquines sin escrúpulos afincados en Valencia.

Dos son los escenarios principales donde se desarrollan los hechos analizados en este artículo, Valencia y Argel, centros urbanos importantes y puertos muy activos del ámbito mediterráneo, pertenecientes cada uno de ellos a una de las dos potencias hegemónicas del último cuarto del siglo XVI: al imperio español la primera y al otomano la segunda, con estructuras políticas radicalmente diferentes y religiones igualmente distintas y enfrentadas. Pero como veremos, aunque se tenían declarada oficialmente la guerra, por el interés y mutua necesidad que tenía uno del otro, mantenían una puerta de comunicación abierta, que no era otra que la del comercio y por ello -salvo en raras ocasiones- eran continuos sus contactos mercantiles y diplomáticos. La presencia de Valencia en estos intercambios de mercancías y personas se debe a la decisión que tomó Felipe II de convertir su puerto en el punto de salida y llegada de los barcos de las redenciones oficiales llevadas a cabo en Argel por los trinitarios.

La inclusión de los mercaderes valencianos completa el campo de estudio de este artículo. Los mercaderes fueron una pieza clave en estos viajes de redención y las novedades documentales que se aportan ofrecen una visión muy viva y real de la ayuda mutua y de las relaciones humanas y económicas que se daban entre captores, cautivos, redentores y mercaderes. Aunque son muchos los mercaderes valencianos con los que trató Cervantes en Argel y que conocemos por otras fuentes, como Baltasar Torres, Onofre Ejerque y Joan Fortuny, por citar solo los más conocidos. Aquí trataremos de dos, Juan Estéfano, antiguo 
compañero de cautiverio de Cervantes y de Francisco Sasso, piloto y mercader, que ayudó al padre Gil y a sus inmediatos seguidores en la búsqueda y contrato de los barcos utilizados en las redenciones trinitarias y sin duda también muy conocido de Cervantes ya desde sus años de cautiverio. Ambos personajes, uno de Ragusa (actual Dubrovnik) y el otro de Génova, estaban por entonces radicados en Valencia y comerciando muy activamente con Argel, sin excluir en sus tratos los rescates de cautivos, a petición de sus familiares, y con los padres trinitarios en los viajes oficiales de redención, y de los que hemos localizado abundante documentación. Sus viajes a Argel eran constantes.

Para la redacción de este artículo, en referencia a su ambientación histórica, geográfica, religiosa, social y comercial me he valido de algunas de las muchas monografías existentes. Aquí vamos a indicar solamente algunas de ellas, que además en su mayoría pueden hallarse en el mercado bibliográfico y en cualquiera de las muchas bibliotecas especializadas del país. Pero lo sustancial y novedoso del artículo procede de fuentes archivísticas, inéditas en muchos casos. Para empezar tenemos que aclarar que en su mayoría se trata de archivos valencianos. Destaca el Archivo del Reino de Valencia (ARV) ${ }^{1}$, que nos ha proporcionado un documento inédito de Cervantes y otros varios referentes al padre Gil. Los documentos nuevos sobre Estéfano y Sasso son numerosos. Este Archivo ya proporcionó en otros tiempos documentos cervantinos de interés, como el privilegio de Felipe II a la madre de Cervantes para que pudiese llevar mercancías no prohibidas con destino a Argel por valor de hasta 2.000 ducados $^{2}$, conservado en su sección de Real Cancillería. También el Archivo de Protocolos del Colegio del Patriarca (APPV) nos ha ayudado con sus riquísimos fondos a esclarecer el asunto de unas apuestas en el que Cervantes se vio envuelto, sin saberlo, a su llegada a Valencia. Y el Archivo Municipal de Valencia, en sus libros de Actas municipales o Manuals de Consells, nos ha abierto una ventana para conocer algún acontecimiento importante que ocurrió en la ciudad durante su estancia en ella. Y fuera de Valencia, el Archivo Histórico Nacional de Madrid (AHN) ${ }^{3}$, que conserva los libros de actas y de contabilidad de las dos misiones redentoras que corrieron a cargo del P. Juan Gil, nos ha aportado datos sobre los mercaderes valencianos y sus relaciones con dicho religioso y sobre su colaboración en el pago de dichas redenciones. La mejor manera de conocer la interacción de redentores y mercaderes en Argel en los momentos de los viajes oficiales de rescate es analizar conjuntamente los documentos del ARV y del AHN.

Para estructurar de alguna manera materiales tan dispersos, los hemos agrupado en torno a los dos viajes de redención de cautivos capitaneados por el padre Juan Gil, es decir, los correspondientes a los años 1581-1582 y 1583, que es cuando concurren -en Valencia y en Argel- todos nuestros

1. En sus Secciones de Protocolos, Real Cancillería, Real Audiencia y Maestre Racional.

2. ARV: Real Cancillería, núm. 620, ff. 32r.-39v. Velasco (1872).

3. AHN: En su sección de Códices. 
personajes. Es inevitable hacer alusiones a hechos anteriores y posteriores de dichos personajes para perfilar o completar su biografía o para señalar que los lazos de amistad y ayuda mutua perduraron con el tiempo, aunque las figuras principales ya no aparezcan directamente en escena, pero sí su recuerdo. Así por ejemplo los mercaderes valencianos continuarán ayudando y colaborando con los sucesores del padre Gil una vez que él desaparezca de la escena, y esto se ve palpablemente en las expediciones de 1587 y de 1591-92.

\section{LA REDENCIÓN DE 1580}

No se había llevado a cabo ninguna redención en Argel desde 1546. Ésta de 1580 marca un hito en la historia de este tipo de iniciativas por la conjunción de tres grandes personajes que en ella intervienen: la de Bernardo Dominici, maestro general de la orden trinitaria que decide volver a poner en práctica el carisma propio de dicha orden religiosa; la de Felipe II, que asume el reto que le propuso el trinitario, dando apoyo legal y financiero a la empresa y planificando el método a seguir en las expediciones redentoras a Argel; y finalmente el padre Juan Gil, que puso toda su voluntad en llevar a cabo esa dura misión de manera que el plan filipino y el toque apostólico que le imprimió el padre Gil -nombrado procurador general de la orden trinitaria- se mantendrá casi invariable hasta mediados del siglo XVIII. Si a ello añadimos que fue precisamente en esta expedición de 1580 cuando se cerró el rescate de Miguel de Cervantes se colige que es la primera y más conocida de las 33 expediciones redentoras que se hicieron entre 1580-1769 a Argel y otras ciudades del norte de África. Esta redención es el modelo que seguirán todas ellas en adelante a lo largo de esos dos siglos y que queda reflejada en los códices titulados Libro de la Redención de cautivos de la Orden de la Trinidad de 1580 a $1769^{4}$, conservados en el AHN de Madrid.

El viaje proyectado a Argel por los trinitarios y patrocinado por la Corona se dio a conocer en la primavera de 1579 . Una vez resueltos los trámites y concedidas las licencias necesarias para el viaje expedidas en la Corte, los padres redentores recorrieron las principales ciudades de ambas Castillas y de Andalucía para recaudar las limosnas destinadas a dicha empresa en los conventos trinitarios, así como las que ofrecieron cofradías, obras pías, instituciones, testamentarías y los adjutorios entregados directamente por familiares afectados por la retención de uno o más de sus miembros en los baños argelinos o atados a los bancos de las galeras turcas. Una de estas ayudas o adjutorios fue el de doña Leonor de Cortinas y su hija Andrea consistente en 300 ducados para la liberación de su hijo y hermano Miguel de Cervantes.

4. AHN: Clero, Códices núm. 118, 119, 120 y 122, limitándonos sólo al siglo XVI, época que tratamos en el artículo. 
A Valencia llegaron los padres redentores a finales de abril de 1580, para ultimar los preparativos para salir cuanto antes a Argel. Además de la recaudación de las limosnas arriba mencionadas, los religiosos se habían ocupado de comprar bonetes en Toledo y aljófar o perlas en Sevilla. En Valencia remataban esta faena comprando tanto en Alcoy, Cocentaina y Segorbe como en la propia ciudad del Turia muchos tejidos en blanco, de diferentes tamaños, que después mandaban teñir de diversos colores, así como mantas y otros textiles al objeto de venderlos en el mercado argelino a un precio más alto, aumentando así el caudal para redimir cristianos carentes de adjutorios. Todas esas mercancías eran muy apreciadas y buscadas en el mercado más selecto de Argel.

Igualmente se ocupaban del alquiler de un barco cuyo patrón estuviese dispuesto a llevar a cabo un viaje, que a pesar de la protección oficial que llevaba, no estaba exento de riesgos. Conocemos el nombre de la saetía que finalmente fletaron en esta ocasión, titulada Santa María y Santa Olalla, y el nombre de su patrón, Antón Torrent. No nos ha llegado el contrato de su fletamento, aunque no variaría mucho del de la expedición de 1583, del que sí tenemos constancia, y del que en su momento hablaremos. No es muy aventurado suponer que le ayudó en localizar dicho navío o saetía Francisco Sasso, mercader y piloto, al que veremos muy vinculado al P. Gil y a sus sucesores en este negocio. Y el contrato estaría redactado en los mismos términos o muy parecidos al que conocemos de la redención de 1583. Este mercader estaba ya desde antes relacionado con Argel, con el mundo de los barcos y sus patronos y con el negocio de los fletamentos y era íntimo amigo de Juan Estéfano, antiguo compañero de fatigas de Cervantes, como en su lugar comentaremos.

La saetía, después que las autoridades inspeccionaron e inventariaron las mercancías depositadas en sus bodegas, y pagados los impuestos y derechos aduaneros y jornales de los funcionarios que intervinieron en dichos trabajos, zarpó el 22 de mayo de 1580 rumbo a Argel, donde atracó una semana más tarde.

Al llegar a esta ciudad, estando presente el rey y varios de sus altos oficiales y funcionarios portuarios se hizo una nueva inspección y tasación de las mercancías llegadas en la saetía. A Hazán Bajá le correspondió el 10 por ciento del valor de la tasación, con lo que compró las mejores mercancías de tejidos y perlas que traía el P. Gil. Además tuvo que comprarle obligatoriamente más de una docena de sus cautivos.

La venida de los padres trinitarios a Argel -el 29 de mayo de 1580- supuso el cambio de la rueda de fortuna en la vida de Cervantes. Pronto se dio cuenta el P. Juan Gil que los conocimientos que éste tenía y el respeto que le profesaban la mayoría de los cautivos e incluso las autoridades argelinas era patente. Así queda reflejado en el testimonio que sobre Cervantes dejó escrito don Diego de Benavides: «huelga y toma contento (el P. Juan Gil) de tratarse y comunicarse con el dicho Miguel de Cervantes, así de asentarlo a comer a su mesa como en lo demás» ${ }^{5}$. Además de poder mantener con Cervantes

5. Información de Argel: A la pregunta XIX. 
conversaciones más elevadas y acordes con su estado, para el padre Gil suponía una fuente de información de primer orden, pues nadie conocía mejor la situación de la mayoría de los integrantes de la colonia de cautivos cristianos de Argel que el mencionado Cervantes. Por ello no es de extrañar el interés personal que tomó dicho padre de tratar con él, pues una de las principales obligaciones que tenía era la de localizar el paradero de los cautivos para los que traían, él y los mercaderes, adjutorios de sus familiares.

El padre Gil no llegó solo, sino que lo hizo acompañado de un grupo de seis mercaderes valencianos, lo que se convertirá en norma en los próximos viajes y cuyas actuaciones veremos perfectamente descritas en el viaje de 1583 gracias a una preciosa documentación de que disponemos, aunque ya se aplicó esta línea de actuación en esta misión de 1580, de la que trataremos en el viaje de 1583. Entre dichos mercaderes se hallaba Francisco Sasso, de quien tendremos ocasión de hablar más adelante ${ }^{6}$, recibiendo de ellos por los fletes de las mercancías que llevaban para vender por su cuenta así como por su pasaje como viajeros 203 doblas argelinas ${ }^{7}$.

A finales de julio ya habían sido rescatados 112 cautivos y sin esperar más regresaron en el barco de la redención a Valencia. El motivo de este rápido e inesperado viaje se debió al ambiente enrarecido que se respiraba en Argel al ver el gran trasiego de barcos de guerra de España que observaban, pues pensaban que Felipe II iba a atacar su ciudad. Al ver que finalmente se dirigieron hacia Portugal, donde el rey estaba preparando su anexión a la corona española, volvió la tranquilidad. Llegaron a Valencia el 5 de agosto de 1580 .

El padre Gil continuó otros ocho meses más en Argel, es decir, hasta marzo de 1581, a lo largo de los cuales liberó otros 44 cautivos. A los tres meses justos de la llegada del padre Gil atracó en el puerto de esta ciudad la flotilla del nuevo rey de Argel, Jaffer Bajá, que venía a sustituir al cruel Hazán Bajá, debido al descontento generalizado que produjo su política corrupta y confiscatoria. Entre sus cautivos venía uno, don Diego de Benavides, un joven de 27 años de edad, cinco años más joven que Cervantes. Era miembro de un ilustre linaje de Baeza, y según el retrato que de él aparece en su acta de rescate consignada en el Libro de la Redención, era «alto de cuerpo, delgado de rostro, pocas barbas y con una señal en el carrillo izquierdo de un golpe que le dieron cuando le cautivaron ${ }^{8}$. Comparado con la mayoría de rescatados que llegaban a España el estado y aspecto físico que presentaba era excepcionalmente bueno. Había sido capturado el año 1574 en la defensa de la fortaleza de Túnez.

6. Francisco Requena, Pere Oliver, Pere Peregrín, Guillem Serrano, Batista Gaspar.

7. AHN: Clero, Códice $118 v$, f. $43 \mathrm{v}$. La dobla argelina equivalía a 6,50 reales castellanos o a 212,50 maravedís.

8. AHN: Códices, núm. 118, fol. 156. 
A los cuatro días de su llegada a Argel fue rescatado por el padre Gil, por importe de 250 escudos de oro, pagados en su mayoría por el propio excautivo, a excepción de la quinta parte que fue aportada por la limosna del Consejo de la Cruzada. Como Cervantes se había convertido en un acompañante asiduo del padre Gil no es de extrañar que en el acta del rescate de don Diego figure Cervantes como testigo del acontecimiento, preludio de lo que le iba a ocurrir a él mismo dieciséis días más tarde.

Lo primero que hizo don Diego de Benavides fue buscar un aposento donde pasar el tiempo lo más cómodamente posible hasta que un barco le trasladase a España de regreso. A continuación preguntó a varios cristianos por los «caballeros y personas principales con quien se pudiese comunicar». Y todos unánimes le informaron: «que principalmente estaba uno muy cabal, noble y virtuoso y era de muy buena condición y amigo de otros caballeros ${ }^{9} \gg$. Benavides no tardó en dar con Cervantes y lo sabemos por boca del propio Benavides: «Este testigo lo buscó y procuró y hallado luego el dicho Miguel de Cervantes se le ofreció con su posada, ropa y dineros que le tuviese: y así lo llevó consigo y lo tiene en su compañía, donde comen de presente juntos y están en un aposento donde le hace mucha merced, en lo cual este testigo halló padre y madre... ${ }^{10}$. Ya no se separarán hasta que una vez pasado el mes de noviembre en Valencia llegó la hora de despedirse, dirigiéndose cada uno a su lugar de origen, Baeza y Madrid.

A Miguel de Cervantes, le llegó la hora de su liberación el día 19 de septiembre, estando ya sentado y bien amarrado en un banco de las galeras que estaban dispuestas para zarpar rumbo a Constantinopla. Sólo el tesón y la amistad que sentía hacia él el padre Gil consiguió doblegar algo la codicia de Hazán Bajá. No vamos a repetir su rocambolesca liberación, pues ya ha sido contada miles de veces. El acta de la misma puede leerse en el Libro de la Redención de $1580^{11}$.

Antes de salir para Valencia Cervantes hizo redactar un informe donde limpió su nombre de las malévolas insinuaciones vertidas contra él por Juan Blanco de $\mathrm{Paz}^{12}$. Declararon los cautivos más prominentes de Argel. Varios eran antiguos soldados de Lepanto, La Goleta y Túnez, y destacaron en sus testimonios las cualidades morales y humanas de Cervantes, su valor y temple ante las dificultades y el servicio y ayuda prestada a sus compañeros de cautiverio. En este importante documento conocido como Informe de Argel, participó también el doctor don Antonio de Sosa, su mayor confidente a lo largo de esos años argelinos y colaborador en sus tareas historiográficas de su destacada obra Topografia e Historia General de Argel. El punto final lo puso el padre Juan Gil estampando su rúbrica y el sello de la redención el día 22 de octubre de 1580.

9. Información de Argel: Respuesta a la Pregunta III.

10. Información de Argel: Respuesta a la Pregunta III.

11. AHN: Clero, Códice 120, f. 32r.

12. Astrana Marín (1948-1958), III, pp. 75ss. 


\section{ESTANCIA DE CERVANTES EN VALENCIA}

Ya no tenía nada que le retuviese en Argel y podía regresar a España con su honor restablecido y defendido de posibles asechanzas. Como de costumbre el padre Gil siguió protegiendo a los rescatados. Pagó al patrón de un bajel, de nombre Antón Francés para que les llevase hasta Denia. En total regresaban seis personas: Cervantes, don Diego de Benavides, Rodrigo de Chaves, Francisco de Aguilar, Antón Gil y Juan Gutiérrez. La fecha de salida de Argel fue el 24 de octubre. A Denia tardarían en llegar de dos a cuatro días, dependiendo del estado de la mar. En la capital de la Marina descansaron un día, y ya por tierra y a pie, recorrieron las 14 leguas que separan Denia de Valencia, haciendo paradas, vestidos ya con el traje de cautivos o al menos con la cruz o escapulario de la orden trinitaria y recibiendo limosnas y hospitalidad en los lugares donde se detenían, como pudieron ser Oliva, Gandía o Cullera. Desde aquí recorrieron el último trayecto por la zona del Saler. Entraron en Valencia justo a comienzos del mes de noviembre o finales de octubre. En primer lugar se presentaron en el convento de Nuestra Señora del Remedio, de la orden de la Trinidad, donde tenían asegurada la estancia y alimentación hasta después de celebrarse la obligada presentación de los cautivos rescatados a las autoridades y la celebración de la procesión a través de las calles de la ciudad desde el mencionado convento trinitario, extramuros de la ciudad, hasta la iglesia metropolitana. La gran procesión se había celebrado en la segunda semana de agosto en la que participaron 108 cautivos redimidos. Ahora sería más modesta, pero aún así llamó mucho la atención como veremos más adelante.

\section{Reencuentro de Cervantes con Juan Estéfano}

Antes de seguir adelante tenemos que dar cuenta del encuentro con su antiguo amigo y compañero de cautiverio Juan Estéfano. Es muy posible que tanto Cervantes como Estéfano conociesen de antemano que se iba a producir dicho encuentro, pues sus contactos con los mercaderes valencianos eran constantes.

Todo lo que conocíamos hasta ahora sobre Juan Estéfano ${ }^{13}$ se limitaba a la información que nos ofreció Astrana Marín en su biografía de Cervantes ${ }^{14}$, que es más bien poco, y tiene su origen en lo que el mismo Estéfano manifestó en la deposición que hizo en Madrid el 1 de diciembre de 1580, ante el requerimiento del doctor Rodrigo de Cervantes, y que ya conocíamos anteriormente por Pérez Pastor ${ }^{15}$. Por ese documento autobiográfico sabemos que era natural de Ragusa y que tenía 34 años de edad en 1580, es decir que

13. También aparece como Juan de Estéfano y Juan Destéfano. Nosotros por economía le llamaremos en adelante simplemente Juan Estéfano, y por ser además la forma más usada en la documentación.

14. Astrana Marín (1948-1958: II, 473, nota 3) y (1948-1958: III, 109-111).

15. Pérez Pastor, 1897: I, 61-62. Repetido en Sliwa (1999: 112). 
era estrictamente contemporáneo de Cervantes. En efecto según esa fecha habría nacido en 1546, un año antes que nuestro Cervantes. Además, en dicha testificación, nos informa de su antigua amistad con Cervantes, nacida en Argel, por haber coincidido como cautivos en casa del arráez Dalí Mamí, y por haber sido el portador de la carta de Cervantes - una vez llegado a Valencia de su cautiverio argelino- a su padre el doctor Rodrigo. Ahora su biografía se enriquece significativamente al aparecer no sólo como un cautivo, sino -una vez liberado de su penosa situación- como un importante mercader afincado en Valencia y que comerció activamente durante muchos años en toda suerte de negocios, incluidos los referentes al rescate de cautivos cristianos prisioneros en los inmundos baños argelinos o sirviendo de galeotes en las galeras corsarias a las órdenes de cómitres despiadados.

¿Quién era este Juan de Estéfano o simplemente Juan Estéfano, pues de ambas maneras es citado en la documentación? Sabíamos ya que era natural de Ragusa ${ }^{16}$, ciudad situada en el Adriático, en la actual Croacia ${ }^{17}$, y mundialmente conocida hoy día como centro turístico, bajo el nombre de Dubrovnik y denominada la «Joya del Adriático». En aquel momento era una república independiente, famosa por su numerosa y activa flota mercante, presente en todos los puertos del Mediterráneo. A lo que parece era miembro de una familia de mercaderes, que en un momento dado, en viaje de negocios por el Mediterráneo, frisando los treinta años de edad aproximadamente, cayó prisionero de los corsarios argelinos. Cuando llegó Cervantes a Argel, tras su captura frente a las costas catalanas el malhadado día de 25 o 26 de septiembre de 1575, se encontró que entre los numerosos cautivos que tenía el corsario Dalí Mamí - uno de los más activos arraeces argelinos-se encontraba el joven Juan Estéfano. Lo primero que tenemos que aclarar es que no era «una de las personas cautivadas con Cervantes en la Galera Sol», como afirma Astrana Marín ${ }^{18}$, pues sabemos que los que iban en dicha Galera, de Nápoles a Barcelona, eran españoles, y todos o en su inmensa mayoría eran soldados y oficiales españoles, en activo o ya retirados después de muchos años de servicio en los ejércitos imperiales. En realidad se trataba de un cautivo más que había caído en las redes de dicho pirata, pero no tenía nada que ver con la Galera Sol. Por otra parte esto coincide con la declaración de Estéfano el

16. Desde el siglo VII a 1204 aunque disfrutaba de una cierta autonomía. De 1204 a 1358 dependió de Venecia y en este año pasó a ser tributaria de Hungría, pero se regía por sus leyes y su gobierno estaba en manos de una aristocracia urbana. Su economía, que llegó a ser muy próspera, se basaba en una flota comercial que operaba a lo largo y ancho del Mediterráneo, con colonias de raguseos en todos los puertos importantes, incluida Valencia, como podemos ver en este artículo. Supo mantener buenas relaciones con el Imperio turco, a pesar de haber conservado la religión católica. Les pagaba un tributo anual y con ello se contentaban. Al ser católica tenía la protección de Roma y del Imperio Español. Su época de esplendor fue el siglo XVI. Tuvo que superar una grave crisis en 1667, con ocasión de un gran terremoto que le causó enormes pérdidas. Sobrevivió como República Independiente hasta 1808, anexionada por Napoleón.

17. No hay que confundirla con otra ciudad, situada en Sicilia, que lleva el mismo nombre.

18. Astrana Marín (1948-1958: II, 473, nota 3). 
1 de diciembre de 1580: "Que este testigo conoce a Miguel de Cervantes mucho tiempo ha y sabe que ha estado cautivo en la ciudad de Argel... y le conoció en el dicho cautiverio... con el mismo amo... y estaban juntos en una casa...». Resulta evidente por lo tanto que le conoció a partir del momento de la llegada de Cervantes a Argel, donde probablemente ya se encontraba detenido Estéfano. Es significativo lo que dice de que estaban juntos en una casa, es decir allí donde Dalí Mamí tenía reunidos a los cautivos que consideraba de mejor posición y de quienes esperaba alcanzar un rescate más elevado, pues Miguel de Cervantes era tenido como un personaje de alta alcurnia y de Estéfano sabían que era hijo de un mercader de Ragusa. Dalí Mamí no se equivocó con Estéfano pues al poco tiempo fue rescatado por sus familiares, cosa que como sabemos no ocurrió con Cervantes que tuvo que permanecer cinco años de cautiverio. La liberación de cautivos era una práctica normal y no era necesaria la presencia de religiosos trinitarios o mercedarios para ello, pues a pesar de las malas relaciones oficiales que existían entre el Magreb y España, los contactos comerciales subsistieron siempre y con dinero por medio era fácil salir de esa situación. Al fin y al cabo la supervivencia de los reinos o bajalatos norteafricanos se sustentaba precisa y fundamentalmente gracias a esos turbios negocios, es decir, al comercio cuyo principal objeto era el tráfico de personas.

Por lo que se refiere a Juan Estéfano, fue liberado muy pronto por sus familiares, probablemente a lo largo de 1576. Poco después vino a establecerse en Valencia y formó parte de la colonia de mercaderes raguseos asentados en la ciudad del Turia. Sabemos incluso, por propia confesión, que su domicilio se encontraba en la parroquia o colación de Santo Tomás ${ }^{19}$. La iglesia de dicha advocación estaba ubicada en parte de los locales que ocupa hoy el Palacio Arzobispal y la jurisdicción de la parroquia se extendía sobre la zona urbana que gira en torno a las calles Mar y Avellanas, entre otras. En alguna de esas calles se encontraba el domicilio de Estéfano

Pronto debió empezar a interesarse por el tema de los cautivos cristianos de Argel, visto como objeto de intercambio comercial sin dejar de ocuparse del negocio de los demás mercancías objeto de comercio, especialmente centrado en la importación de toda una lista de productos naturales o manufacturados. Estéfano pronto se relacionó con el piloto-mercader Francisco Sasso, natural de Génova, que ya llevaba muchos años establecido en Valencia y que también se había especializado en los tratos con Argel.

El hecho de haber estado anteriormente en Argel, conocer su ambiente y desenvolverse en su jerga lingüística le pudieron mover a dedicarse a mercadear en exclusiva con esta ciudad, tanto en el sentido de importar las mercancías que allí se ofrecían para comerciar y ser útiles en Valencia como en atender las peticiones de los familiares que tenían seres queridos retenidos en las cárceles o baños de Argel. 
A Cervantes lo volvió a ver de nuevo una vez llegado a Valencia tras su liberación, pues Estéfano no viajó esta vez a Argel en la nave redentora de 1580 con el grupo de los mercaderes valencianos habituales. En esta ciudad por lo tanto se reencontraron los dos viejos amigos y recordarían los amargos días de su cautiverio cinco años atrás. Pasaron juntos unos días en Valencia. Sin duda le ofrecería su casa, sita en la colación o parroquia de Santo Tomás. Pero debió declinar su ofrecimiento pues iría a hospedarse con sus amigos, especialmente con don Diego de Benavides en alguna de las posadas que abundaban en la próspera ciudad del Turia. Además Estéfano tenía que emprender un viaje urgente de negocios a Madrid y fue entonces cuando le confió Cervantes una carta para su padre el doctor Rodrigo Cervantes, donde le contaba los pormenores de su liberación y el dinero que se había empleado en su rescate, las deudas que tenía contraídas con los mercaderes y la orden trinitaria y las soluciones que se podían dar a un asunto tan enojoso e inoportuno. Si echamos de menos tantos documentos perdidos, cuánto más esta carta, donde aflorarían la alegría por la libertad recobrada y los pesares por las cargas económicas contraídas.

Estéfano, durante su estancia en Madrid se albergó en una posada de la calle Toledo. Tuvo tiempo, además de solventar sus negocios, para hablar con los padres de Cervantes, y a petición de Rodrigo declaró el 1 de diciembre de 1580 ante el licenciado Prieto, teniente de Corregidor de Madrid, testificando cómo había sido rescatado en Argel por la suma de 500 ducados y haber quedado manco o «estropeado» ${ }^{20}$ en Lepanto. Son muchos más los datos biográficos inéditos que he logrado obtener en la investigación, pero que aquí me limitaré a sintetizar en nota ${ }^{21}$.

\section{Regularización de sus deudas}

Una vez cumplido el ritual de la procesión y de haber saludado a su amigo de cautiverio Juan Estéfano el principal asunto que debía atender era el enojoso asunto de la deuda contraída con los mercaderes valencianos que le

20. El término de "estropeado" es el que se empleaba entonces para decir que habían quedado mancos, cojos o con otra minusvalía. En las listas de rescatados de Argel de estos años aparecen varios "estropeados" con las mismas características que Cervantes, es decir con heridas graves en un brazo.

21. Sus actividades comerciales aparecen fundamentalmente en la sección de Peaje de Mar (ARV) y que me ha proporcionado el profesor Roberto Blanes, con datos referidos a mercaderes valencianos que traficaron con Argel en el siglo XVI, especialmente los referidos a Estéfano y Sasso. Agredezco muy sinceramente dicha información. Esta actividad comercial entre Valencia-Argel y viceversa transcurrió entre 1584 y 1604. Sus viajes a Argel fueron muy numerosos y los productos que importaba más frecuentemente eran: cueros, lana, cera, alfombras, dátiles, índigo etc. En uno de sus viajes logró incluso comprar una saetía en Argel, procedente de una captura de un corsario argelino a un comerciante de Vinaroz, con la que estuvo comerciando en el transporte de mercancías entre los puertos de la costa mediterránea española. Estéfano desapareció de la documentación en 1604. ¿Volvió a Ragusa a acabar sus días? 
habían adelantado algo más de mil reales castellanos para comprar con ellos comida y vestido principalmente en los años de cautiverio. El importe de dicha deuda está avalada por el testimonio de sus compañeros y confidentes Rodrigo de Chaves y Francisco Aguilar ${ }^{22}$. Desconocemos el nombre del mercader o mercaderes que le adelantaron esos mil reales ${ }^{23}$. El pago de deuda contraída con el padre Juan Gil y la orden trinitaria para pagar su rescate ya había sido registrada en los libros de la redención antes de salir hacia España por el notario de la redención, que ascendía a otros dos mil reales castellanos ${ }^{24}$.

¿Por qué pasó Cervantes un mes largo en Valencia? Normalmente los excautivos una vez cumplida su obligación de asistir a la procesión y de formalizar el pago de sus deudas, si las tuviesen, lo que se hacía ante notario al día siguiente, salían de inmediato a sus lugares de origen. La generosidad de su amigo don Diego de Benavides que correría con los gastos de hospedaje, alimentación y otros, tal como ya lo había hecho en Argel, puede ser la clave de esa larga estancia en la ciudad del Turia. Otra explicación podría encontrarse en que precisamente ese tiempo era el plazo que daban los mercaderes acreedores a sus deudores para que hiciesen efectivo el pago del dinero adelantado ${ }^{25}$. Pudo quedarse Cervantes un mes bien cumplido hasta que le llegase la respuesta de su padre a la carta que le entregó en mano su amigo Juan Estéfano, y el dinero que adeudaba tal como se indicaría en dicha carta. También podemos pensar, aunque no está probado que su amigo don Diego le ofreciese pagar dicho importe o parte del mismo, pues pertenecía a una familia de muchos recursos económicos, como lo manifiestan los palacios renacentistas que por entonces levantaban en Baeza y otros lugares del contorno y la capilla funeraria familiar que fundaron y dotaron muy generosamente en una iglesia de dicha localidad andaluza.

Otro asunto que sin duda ocupó a Cervantes los primeros días pasados en Valencia fue la manera de vender a algún mercader el privilegio otorgado por Felipe II a su madre doña Leonor de Cortinas para que pudiese llevar a Argel mercancías por valor de hasta 2.000 ducados, y con el beneficio de su venta pagar lo que faltaba de su rescate. La verdad es que resulta extraño que por una parte Cervantes conociese y tuviese tan buenos amigos mercaderes en

22. Sliwa, 1999: 1580/12/18-(2) y 1580/12/19. Estos dos personajes hicieron el viaje junto con Cervantes y don Diego de Benavides desde Argel a Valencia, y Chaves incluso continuó con Cervantes hasta Madrid.

23. Debe ser buscado entre Onofre Ejerque, Joan Fortuny, Bartolomé Torres o Francisco Sasso, que por aquellos años eran los mercaderes que con mayor asiduidad acudían a Argel, para sus negocios, entre ellos rescatar cautivos con el dinero que les adelantaban sus familiares. Debemos señalar entre los posibles candidatos a Onofre Ejarque, con el que tanto intimó en la última atapa de su destierro y a Joan Fortuny, al que años más tarde el propio Cervantes avaló con 100 ducados para que pudiese cobrar una deuda de 4200 reales castellanos que había adelantado a Antonio Centeno, un rescatado desagradecido, que se resistía a liquidar dicha deuda.

24. Idem. Este documento no nos ha llegado y por lo tanto desconocemos las condiciones y plazos dados para saldar dicha deuda.

25. Así aparece en varias escrituras de los Protocolos 154 y 155 del ARV (de 1583 y 1587) acordadas entre mercaderes y excautivos rescatados de orden de sus familiares y para gastos personales que les habían adelantado dichos mercaderes. 
Valencia y que a la hora de la verdad ninguno de ellos se prestase a comprar dicha licencia real y que tuviese que ser un portugués quien lo hiciese finalmente años más tarde. ¿Cómo es posible que Nofre Ejarque, Baltasar Torres y Joan Fortuny, que le ayudaron en sus apuros económicos en sus tiempos de cautiverio no adquiriesen los derechos de dicho privilegio y le ayudasen con ello a salir del angustioso problema en que estaba metido?

Dicho mercader portugués, que aparece en los documentos conservados de Felipe Ayerbe, llamado Francisco de Aguiar, se ocupó por entonces y durante varios años en la redención de cautivos portugueses ${ }^{26}$, teniendo como base de operaciones el puerto de Valencia, pues no olvidemos que por entonces Portugal se había unido a Castilla. Por aquellos años las cárceles de Argel y los bancos de las galeras de los corsarios estaban atestados de portugueses caídos en poder de los musulmanes tras la derrota del ejército de Don Sebastián en la batalla de Alcazarquivir del 4 de agosto de 1578. Fue él quien en última instancia compró dicho privilegio pero ya en 1584. La pérdida de los protocolos del notario Felipe Ayerbe nos ha privado también de saber los términos exactos en que se llevó a cabo la transacción de la venta de dicha licencia real.

\section{De visita por la ciudad y sus alrededores}

Así pues, en espera de ayuda económica o simplemente por el placer de disfrutar una temporada, en compañía de sus amigos Benavides y Rodrigo Chaves se dedicó a conocer y disfrutar la ciudad que a decir de los viajeros que por entonces la transitaron era de las más famosas, ricas y dignas de visitarse de España. Contaba por aquellos días con unos 75000 habitantes y con edificios notables: la catedral, la Casa de la Ciudad o Ayuntamiento, hoy desaparecido; el palacio de la Generalitat, que por entonces estaba casi acabado en cuanto a su fábrica arquitectónica se refiere; la Lonja, que constituía un caso especial, tanto por su arquitectura en gótico civil, esbelta y elegante, como por ser el centro principal de la actividad comercial de la ciudad; el Hospital era otro conjunto impresionante de edificios, y aún más por su gestión y funcionamiento etc.

La ciudad estaba encorsetada por sus murallas medievales, musulmanas y cristianas, abiertas por siete puertas de acceso, algunas de notable belleza. Sus calles eran estrechas y de trazado tortuoso. En contraste, solo con salir fuera de ellas, la huerta se extendía por doquier. Hay que reconocer que la estación invernal, que es cuando llegó Cervantes de Argel, no era la más propicia para apreciar el campo y la huerta valenciana y no pudo disfrutar del colorido de sus flores, del aroma del azahar de sus naranjos, del verdor de las innumerables hileras de moreras, base de su poderosa industria sedera, etc. 
Un poco más alejada se encontraba la Albufera, que siempre impresionaba al visitante, al amanecer y al atardecer especialmente, con el vuelo constante de las aves migratorias que esas sí ya se hallaban en dicho mes, recién llegadas del norte de Europa.

También había varios Corrales de Comedias, como el famoso de La Olivera, espectáculo muy popular y multitudinario. Lo más seguro es que asistió a más de una representación en compañía de sus amigos. Pasear simplemente por sus calles y observar lo que veía a su alrededor le resultaba muy instructivo. Pudo percibir en su discurrir por la urbe el carácter extrovertido y bullicioso de los valencianos. La limpieza de las calles llamaba la atención de los viajeros, si las comparaban con las de otras ciudades. Otra cosa que le impresionó fue la expresividad de la lengua valenciana y el acento dulce de la misma y de lo cual dejará constancia en alguno de sus escritos. Pudo presenciar algunas de sus fiestas y costumbres; saborear su cocina, deleitarse con su música, sorprenderse de la actividad de sus mercados; admirar sus industrias sederas y cerámicas, etc.

Especial atención prestó Cervantes a contactar con los autores valencianos entonces vivos como Gaspar Gil Polo (1516-1591), poeta y jurisconsulto, autor de la Diana Enamorada, obra del género bucólico y pastoril, y una de las pocas que salvó en el «donoso escrutinio» y a la que imitó en La Galatea; a Cristóbal Virués (1550-1609), estricto contemporáneo suyo, militar también, y que como él combatió en la gloriosa jornada de Lepanto, y de quien también salvó su obra El Monserrate de la hoguera de los libros. Y sobre todo visitó en su famosa librería al ya anciano Joan de Timoneda (1518-1583), quien según él «en vejez al tiempo vence». Era un poeta, escritor y editor. Introductor de los cuentos cortos al estilo italiano en el mercado libresco nacional, ampliando así la actividad económica de este sector, pues resultaban obras económicas, de lectura fácil y entretenida, que se vendían en toda España y se exportaban incluso a América en época temprana. Fue el editor de las obras de Lope de Rueda $^{27}$, uno de los autores preferidos de Cervantes y el mismo Timoneda cultivó con éxito el género teatral. Fue él con su librería uno de los que más contribuyó a implantar el castellano en la sociedad valenciana. Además en su librería tenía establecida una tertulia, donde se reunían escritores jóvenes y maduros, y donde pudo conocer nuestro escritor a poetas y dramaturgos, entonces en plena juventud. Entre ellos podemos citar a Agustín de Tárrega (1554-1602), Gaspar Aguilar (1561-1623) y Guillem de Castro (1569-1631). Y allí, en dicha librería, que sin duda frecuentó durante su estancia valenciana, compró algunas obras literarias de Timoneda y de otros escritores, de que estaba bien surtida dicha librería.

En relación con los escritores estaba la industria de la imprenta. Ya desde finales del siglo XV Valencia se había consolidado como la ciudad española que contaba con el mayor número de imprentas. Primero estuvieron regenta-

27. Pero las imprimió en los talleres tipográficos de Mey. 
das por extranjeros, pero luego fueron sustituidos por nativos. Si no fue aquí donde se imprimió el primer libro en España ${ }^{28}$ fue en Valencia donde se dio la mayor actividad tipográfica a lo largo de los siglos XV y XVI. Cuando llegó Cervantes a Valencia, camino de Madrid, la imprenta de mayor actividad era la de los Mey, regentada durante un siglo (1535-1635) por miembros de dicha familia, de origen flamenco. Y de los tórculos de la imprenta de Pedro Patricio Mey, salió la Primera Parte del Quijote el mismo año en que apareció en Madrid, es decir en 1605.

\section{Unas apuestas que dieron mucho que hablar}

Como novedad damos a conocer dos noticias biográficas de Cervantes que nos brindan los archivos valencianos. En una de ellas aparece incluso su nombre junto al de su amigo inseparable don Diego de Benavides y forma parte de un acontecimiento que dio mucho que hablar en la ciudad durante muchos meses.

Al tiempo de la llegada de Cervantes de Argel había un tema de conversación dominante en la ciudad y la opinión pública de Valencia estaba dividida en dos bandos: los que pensaban que un tal Jeroni Planelles, estaba vivo y los que le daban por muerto. Se trataba de un joven pescador del Grao que un día salió de su casa enrolado en un barco de carga. En un momento dado, se acusó a Pere Clauquell y Nadal Monserrat, mallorquines, como autores del supuesto homicidio de dicho Planelles. Llegaron los incriminados a las Torres de Serranos, en el mes de mayo, donde fueron encarcelados, pues por entonces cumplían la función de prisión común de la ciudad. Desconocemos muchos detalles y fechas precisas de los acontecimientos y los fundamentos en que se basaba dicha detención.

Como había una colonia de mercaderes y hombres de mar de Mallorca residentes en Valencia no faltaron quienes se ocuparon de ayudar a los rehenes, señalándose entre ellos Miquel Tauler ${ }^{29}$, un comerciante especializado en la venta de quesos y atún ${ }^{30}$ quien se ocupará muy de cerca de gestionar la defensa de los rehenes y de ir a la cárcel a visitarles frecuentemente y llevarles comida.

El juicio se llevó a cabo en los meses de agosto y septiembre. Poco antes había llegado desde Mallorca Joan Matos, patrón de navío, el cual afirmó haber visto a Jeroni Planelles en Mallorca en torno a la fiesta de Pentecostés de 1580 (en los meses de mayo o junio), lo que fue testificado también

28. Hasta hace poco se daba por cierto que aquí se imprimió el primer libro de España. Hoy se conocen libros editados con anterioridad a 1470, que es el año de la impresión de Obres trobes en lahors de la Verge Maria.

29. En la documentación aparece a veces como Miquel Taulell, pero la forma correcta era la de Tauler

30. Siempre se le denomina como "formatger i tonyiner". 
por otros marineros de su tripulación. Esto causó un revuelo enorme en la ciudad, donde se seguía apasionadamente dicho proceso. Pero mucha gente seguía pensando que el pescador del Grao había sido asesinado. Faltaba ahora saber el lugar exacto donde se encontraba dicho Jeroni Planelles, pues había desaparecido de la circulación en Mallorca. Había que dar con su paradero actual para salvar a los acusados de su condena a muerte, y de paso, si se podía, liberar del cautiverio al desafortunado pescador.

Como en una obra teatral podemos distinguir cinco actos en el desarrollo de los acontecimientos. En el primer acto entra en escena Miguel de Cervantes. Acababa de llegar a Valencia procedente de Argel, lo que ocurrió en torno al día 1 de noviembre, festividad de Todos los Santos, o incluso uno o dos días antes, según el testimonio de un testigo: «...en la festa de Tots Sants... o poch abans arribaren a la present ciutat dos catius cristians, los quals eran del regne de Castella...» ${ }^{31}$. Y ¿quienes eran esos dos cautivos?: "Lo hu dels quals se deia CERVANTES ${ }^{32}$ y l'altre DON DIEGO [en blanco], los quals també públicament digueren y testificaren com en la ciutat de Alger, terra de infels, restava viu lo dit Hierony Planelles...» ${ }^{33}$. Esto lo dice una de las partes que interviene en un pleito que sostendrá con Tauler en mayo de 1581, apenas cinco meses después de haber pisado Cervantes la ciudad de Valencia. La presencia a su lado de don Diego, que no es otro que don Diego de Benavi-

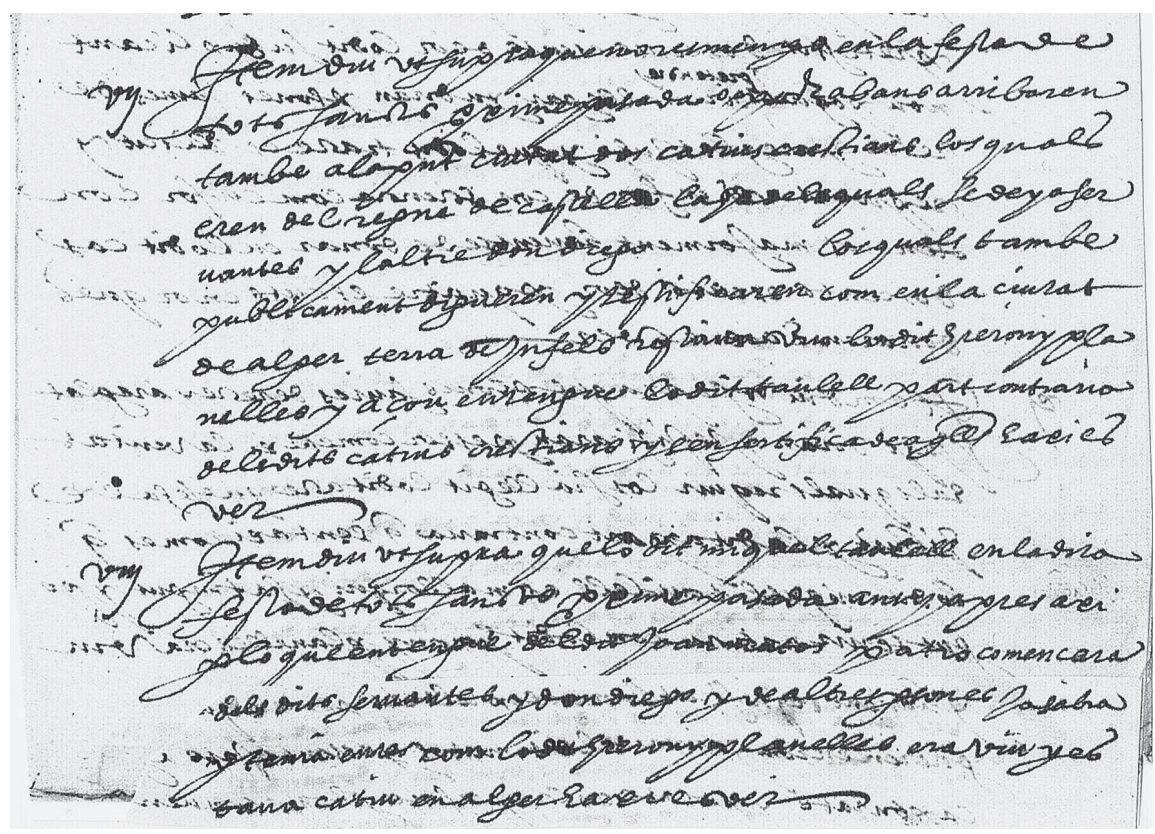

31. ARV: Real Audiencia, Procesos, 2ª Parte, Letra M, exp. 651, f. 9rv. Ver: Apéndice Documental, núm. 1.

32. En el original: Servantes.

33. ARV: Procesos, $2^{\mathrm{a}}$ Parte, Letra M, exp. 651, f. 9rv. Ver: Apéndice documental, núm. 1. 
des, natural de Baeza, el nuevo amigo que Cervantes encontró al final de su cautiverio en Argel y que desde entonces se hicieron inseparables hasta su regreso a España y durante su estancia en Valencia. Es natural que se nombre antes a Cervantes que a don Diego, pues realmente quien pudo informar bien a Tauler sobre Argel y los cautivos, y muy concretamente de Jeroni Planelles fue Cervantes, que era quien conocía a fondo Argel y a los individuos que integraban la colonia de cautivos españoles. Don Diego apenas permaneció en Argel mes y medio, como comentamos en su lugar y poco podía informar y menos aún de una persona concreta. Este nuevo documento nos confirma su amistad con el alcalaíno universal y que estuvo con él en Valencia en sus días de estreno de su libertad.

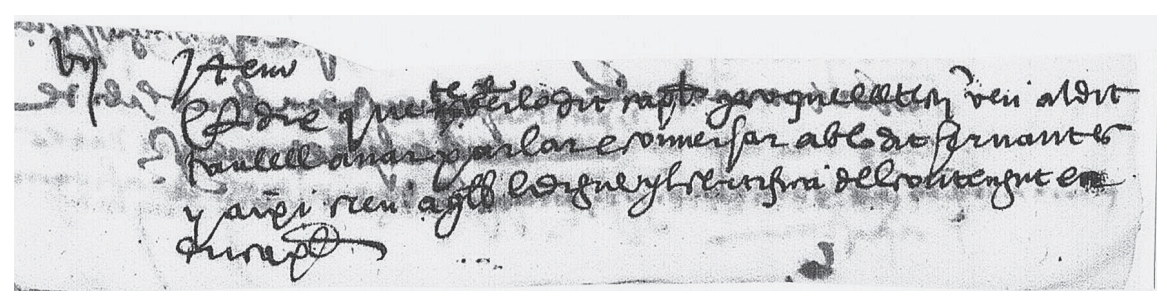

Sabemos por lo tanto que Miquel Tauler se acercó a Cervantes en busca de información sobre Jeroni Planelles, pues tenemos la declaración de otro testigo $^{34}$, que además se declara amigo de Tauler: «E dix... que ell testimoni veu al dit Tauler anar parlar e conversar ab lo dit Cervantes... $\rangle^{35}$. No se trató de un simple encuentro y de una conversación rápida, sino larga y distendida, pues puntualiza: «parlar e conversar». ¿Cuál era el motivo que tenía dicho Tauler para tratar tan detenidamente con un cautivo que acababa de llegar de Argel, ya rescatado, a Valencia? Su interés era doble. Por una parte el patrón Joan Matos y otras personas le había certificado que Planelles estaba vivo, pero no era suficiente, necesitaba dar con su paradero actual. Es posible incluso que ya sospechase que estuviese prisionero, como sucedió, pero aún así necesitaba más información. Y la persona que mejor se la podía dar se encontraba en ese momento de paso en Valencia, pues nadie mejor que Cervantes conocía Argel y a los cautivos que la poblaban. No hace falta más que leer la Topografía e Historia General de Argel para darse cuenta de ello. Y si Tauler sospechaba de que Planelles se hallaba en Argel, Cervantes le certificó plenamente de ello. Además le informaría en manos de quién se hallaba, precio que le podría exigir y la mejor manera de lograr su rescate.

Todo esto se lo preguntó presentándose como alguien que estaba interesado en rescatar a dicho cautivo, sin desvelarle sus planes verdaderos. Pues además de ayudar al propio Planelles y sus paisanos encarcelados, estaba urdiendo

34. Su nombre era Bertomeu Navarro, pescador de profesión.

35. ARV: Procesos, $2^{\mathrm{a}}$ Parte, Letra M, exp. 651, f. 22r. Ver: Apéndice documental, núm. 3. 
un plan de gran rentabilidad económica, que le resarciría con creces de todos los gastos que había tenido en ayudar a dichos presos mallorquines, y los que tendría que sostener para llevar a cabo el rescate de Jeroni Planelles.

Curiosamente en cuanto tuvo la certeza de que Planelles se encontrada efectivamente cautivo en Argel, el nombre de su patrón y el lugar preciso donde habitaba, comenzó a poner en práctica el proyecto que llevaba ya madurando de un tiempo a esta parte. Pues será precisamente el día 7 de noviembre cuando empiecen las apuestas en torno a la vida o muerte del dicho Planelles, alentadas por él en la sombra, aprovechando la división de pareceres que había en la ciudad. El que más información tenía al respecto era él, sobre todo después de haber hablado con Cervantes. Lógicamente Cervantes no hizo más que ayudar a una persona que aparentemente no tenía otro objetivo que ayudar a un pobre cautivo a salir del abismo en que estaba sumido. Ni remotamente podía figurarse nuestro escritor el trasfondo que había detrás de aquella aparentemente noble actitud. La entrevista pudo tener lugar bien en un mesón o en la casa de hospedaje en que se habían instalado Cervantes y sus amigos Benavides y Chaves.

Posiblemente nunca se había celebrado en Valencia una apuesta de estas características ni se celebrarían en el futuro, pues después del escándalo que causó este asunto, una vez solucionadas en los tribunales las numerosas apelaciones que hubo, las autoridades prohibieron este tipo de juegos de azar. Hay que reconocer que montó un negocio muy bien tramado, y como había componentes jurídicos muy bien perfilados es casi seguro que estuviese asesorado por algún hombre de leyes, pues su profesión de mayorista de alimentación no parece la más adecuada para salir airoso en un asunto tan complejo y arriesgado.

De momento hay que resaltar la participación de Cervantes en esta trama, por supuesto sin apercibirse de ello ni por lo tanto haberse beneficiado de los abundantes recursos que proporcionó a su muñidor principal, Miquel Tauler, y a otros que se decidieron por la apuesta ganadora, es decir, que Jeroni Planelles estaba vivo. Entre estos había alguno que era amigo de Tauler y colaboradores suyos en la empresa o negocio, pues esto no lo podía hacer una persona sola. Los otros beneficiados fueron los dos incriminados, que acabaron siendo excarcelados y que de no haber mediado el interés de Tauler, -viciado es verdad por el afán de lucro y jugando con ventaja- habrían acabado en la horca en la plaza pública del mercado.

El segundo acto empezó cuando Tauler, apenas tres o cuatro días después de su entrevista con Cervantes, comenzó a poner en práctica su proyecto. Fue en el entorno de la Lonja donde empezó a captar a personas solventes dispuestas a apostar sobre el asunto que por entonces estaba en boca de todo el mundo y que se reducía a tomar partido por si Planelles estaba vivo o muerto. La mayoría pensaba que su posición al respecto era la correcta. Prevalecía la opinión de que estaba muerto pues de lo contrario ya habría dado señales de vida. Además el hecho de que había unas personas encarceladas y de que la justicia a pesar de haberse celebrado el juicio no les había excarcelado 
abonaba dicha opinión. Otros pensaban lo contrario, algunos porque habían oído rumores de que había sido visto vivo en Peñíscola y Mallorca, y otros porque eran conocedores de que no sólo estaba vivo sino que en esos días se encontraba en Argel. Este era el gran secreto que había confirmado Cervantes a Tauler y éste a sus compinches mallorquines. Incluso cuando alguien comenzó a difundir la noticia de que Jeroni Planelles se hallaba en Argel, los «conjurados» se encargaron de difundir la noticia de que ese Planelles no era valenciano sino alicantino, con lo cual la confusión y división de pareceres continuó entre el público. Aparece claramente esta opinión en un testimonio judicial del propio Tauler, atribuyéndola a la opinión general de la gente: «... sentí a dir per la present ciutat, ell responent, [es decir, Miquel Tauler] que los dits catius deien que en la dita ciutat de Alger y havia un Hieroni Planelles, emperò que no sabien si era valencià, i dient-ho, ell responent, a d'algunes persones en Lonja, deien que lo dit Planelles que estava en Alger no era lo de València sinò que era un Planelles de Alacant» ${ }^{36}$.

La propuesta era fácil: el que apostaba que Jeroni Planelles estaba muerto prometía pagar al otro una alta cantidad de dinero, normalmente 100 libras valencianas ${ }^{37}$ o 100 escudos castellanos $^{38}$ en el momento mismo que apareciese vivo y se pasease por la ciudad dicho Planelles, «que se decía estar muerto, por haber sido asesinado por unos malhechores que se hallaban detenidos en las Torres de Serranos de orden del Justicia Criminal de Valencia». Esta frase, incluida en el contrato, era un verdadero reclamo para que se apostase por la propuesta que aseguraba que Planelles estaba muerto. Además, se ve la mala fe de los impulsores de la apuesta y que jugaban con ventaja, esta vez no con cartas marcadas o con dados trucados, sino con la posesión de conocimientos privilegiados sobre el estado vital de la persona sobre la que se apostaba.

No se exigía cantidad alguna por adelantado, como es lo normal en todo tipo de juegos de azar. Es más, los que apostaban por la opción de que Jeroni estaba vivo, fingiéndose los generosos, adelantaban el pago de una mínima cantidad, entre el dos y el seis por ciento del total de la apuesta, pero a cambio de esa supuesta generosidad, se les obligaba a renunciar a cualquier alegación jurídica que pudieran presentar posteriormente ante los tribunales sobre cualquier indicio de que pudieran haber tenido información privilegiada sobre la existencia del supuesto asesinado ${ }^{39}$.

Las apuestas tuvieron un impacto brutal. Aunque no se conservan todos los contratos de las mismas, como es natural, sí que nos han llegado un número

36. ARV: Real Audiencia, Procesos, Parte $2^{\mathrm{a}}$, Letra M, exp. 651, f. 12r. Ver: Apéndice documental, núm. 2.

37. La libra valenciana valía aproximadamente lo mismo que un escudo castellano.

38. Son pocos los casos en que se apostaron cantidades menores (de 25 o 50 libras o de 25 o 50 escudos), o cantidades mayores (de 200 o 300 libras o de 200 o 300 escudos).

39. "Et etiam renúncia a qualsevol dret y acció [que] tinga contra aquell per rahó de qualsevol notícia, sciència [que] tinga de la vida del dit Planelles..." 
considerable de ellos, en total 140, más o menos la mitad de los que se escrituraron. En efecto, sabemos que se llegaron a jugar en estas apuestas unas 30.000 libras valencianas, que a una media de 100 libras por apuesta, serían unas 300, lo que quiere decir que participaron 600 personas, si bien como algunos apostaron varias veces el número de apostantes debe ser reducido ${ }^{40}$.

Las apuestas empezaron a escriturarse el 7 de diciembre de 1580, pocos días después de la larga entrevista que sostuvieron Miguel de Cervantes y Miquel Tauler, donde le informó muy convincentemente sobre la situación en que se encontraba Planelles en Argel, y con tal revelación no esperó más para iniciar las apuestas. En un solo mes se hicieron 55 apuestas contabilizadas en una sola notaría de las dos notarías que las recibieron del 7 de noviembre al 3 de diciembre. Las apuestas se hicieron ante notario y con todas las garantías legales para que se hiciese efectivo en su día el pago, dándoles la misma fuerza legal que a los contratos mercantiles que se pasaban en el Tribunal de la Lonja de los Mercaderes de Valencia ${ }^{41}$.

El tercer acto puede ser identificado con las gestiones que hicieron los confabulados mallorquines para rescatar a Jeroni Planelles y asumir los gastos ocasionados por ello: pago del rescate a su amo, gastos de los mediadores que fueron a Argel en su búsqueda, tanto por sus jornales como por la manutención y los viajes de ida y de vuelta con el cautivo ya liberado, además de los impuestos que cobraban por la liberación diversos funcionarios argelinos. Todo esto se llevó a cabo entre finales y marzo y primeros días de abril de 1581. El cautivo llegó a Valencia el 11 de abril. Compensó a los promotores el negocio, pues les proporcionó sustanciosas ganancias. Así por ejemplo sabemos que Miquel Tauler firmó al menos 38 apuestas, con un promedio de 100 libras cada una de ellas, lo que hace un montante de 3500 libras las que se embolsó.

Estamos ya en el cuarto acto. Se dieron por concluidas las apuestas. Era el momento de recoger los ganadores los caudales que se habían jugado en las oficinas notariales. Vimos que la única condición que se exigía para cobrar las apuestas era que se presentase vivo en Valencia el tal Jeroni Planelles y se pasease por sus calles. Y el más interesado en el asunto por las cantidades que había apostado era Miquel Tauler y fue él también quien se ocupó de escenificar y presentar al público a Planelles como no podía ser de otra manera, por el enorme interés personal que tenía en ello. Fue el día 12 de abril de 1581 -justo al día siguiente de su llegada a Valencia- y lo hizo en la propia Lonja, que era donde se habían escriturado las apuestas. Presidiendo la mesa estaba un alguacil extraordinario del rey, además del notario Joan Vicente Roures, ante quien se habían formalizado al menos la mitad de las apuestas. Además de Miquel Tauler, quien había preparado todo, y «... por su interés», como

40. Las apuestas se encuentran en el APPV, Protocolos, núm. 20302 y 20303 de los años 1580 y 1581 respectivamente, pertenecientes al notario Joan Vicent Roures. Se sabe que otro notario, Tomás Martí también escrituró dichas apuestas, pero sus protocolos de esos años han desaparecido.

41. Al menos fueron dos las notarías que registraron las apuestas, la de Joan Vicent Roures y la de Tomás Martí. Sólo se conservan los protocolos del primero. 
explicita el documento, se encontraba mucha gente que no quería perderse el espectáculo: «i de molta altra gent copiosa», dada la expectación que había causado el caso. Ante ellos se presentó Jeroni Planelles, acompañado de su padre y de un hermano suyo, «per a què dites apostes tinguen effecte». Dichos familiares confirmaron que se trataba de su hijo y hermano y lo mismo certificaron unos testigos presentados para la ocasión. Para completar los requisitos exigidos en la apuesta se hizo pasear al dicho Jeroni por la Lonja varias veces, para que fuese público y notorio ${ }^{42}$.

Sólo quedaba el quinto y último acto. Una vez cumplidos los requisitos exigidos por el contrato llegó la hora de hacer efectivo el pago de las cantidades acordadas. Una buena parte de los apostantes pagaron religiosamente a lo largo de los cuatro primeros meses después de la aparición pública de Planelles. Pero como se vio enseguida que había sido una apuesta fraudulenta, por saber de antemano que el supuesto difunto gozaba de buena salud, algunos se resistieron a hacer efectiva la deuda e incluso acudieron a la Real Audiencia en amparo de sus reclamaciones. Pero la Audiencia se mantuvo firme en la interpretación del documento de las apuestas, donde los apostantes habían renunciado a acogerse a ese resquicio que normalmente hubiese bastado para anular la obligatoriedad del pago, y poco a poco no tuvieron más remedio que hacer efectiva la cantidad acordada, como sentenció la Real Audiencia a pesar del tesón de algunos querellantes por agotar todos y recursos que la ley les permitía. Por ello de abril de 1581 a mayo de 1582, se liquidaron la mayoría de las deudas. Unos pocos, más reacios a liquidar sus compromisos, tardaron algunos años más en saldar sus cuentas. Es verdad que en el fondo los magistrados veían que ese tipo de apuestas eran contrarias a la moral y buenas costumbres pues se ponía en peligro la vida del individuo objeto de la apuesta y de hecho las autoridades prohibieron al poco tiempo celebrar esa clase de apuestas.

No sabemos si llegó a oídos de Cervantes la evolución y el final de la farsa organizada en torno a estas apuestas, y de su contribución involuntaria con la información que aportó y de la que se aprovecharon unos desaprensivos a sus espaldas. No es fácil que llegase a estar informado de ello pues faltaban cinco meses para que estallase el escándalo, y él estaba ya lejos del escenario de los acontecimientos. De haberlo sabido quizá nos hubiese divertido con una de sus novelas ejemplares o una obra teatral que escenificase este curioso incidente en el que se vio incurso nuestro eximio escritor.

\section{Exequias reales por doña Ana de Austria}

Además del episodio de las apuestas en el que involuntariamente se vio implicado Cervantes durante su estancia en Valencia hay otro acontecimiento 
que sin duda le impresionó, por las escenas que presenció y por traerle a la memoria acontecimientos similares que había vivido en Madrid doce años antes, en vísperas de su salida precipitada de la corte. Me refiero a la solemne celebración de las «honras, exequias y capilla ardiente» que se celebró en la catedral durante los meses de noviembre y diciembre de 1580 en señal de duelo por la muerte de Doña Ana de Austria, cuarta esposa de Felipe II.

A finales de enero de 1580 moría sin descendencia el rey de Portugal Don Enrique. Por ley le correspondía la corona portuguesa a Felipe II por ser el heredero directo más calificado. La mayoría de la nobleza y del alto clero estaban de acuerdo. Pero se interpuso Don Antonio, prior de Crato, que también aspiraba a la corona. A su momento se descubrió y publicó que era bastardo, hijo de un príncipe y de una judía conversa. Mal aconsejado por facciones anticastellanas llegó a proclamarse rey. También se oponían a ello, pero por otras razones Francia, Inglaterra y el mismo papa, que no veían con buenos ojos que con la anexión de Portugal se aumentasen las riquezas y el poder de la monarquía hispánica.

Felipe II desde el primer momento decidió asumir la responsabilidad y dirigir las operaciones diplomáticas, políticas y militares directamente y desde un lugar cercano al escenario de los acontecimientos, y ya a principios de marzo se trasladó con un grupo de funcionarios a Badajoz, en la misma frontera con Portugal. La reina decidió acompañar a su marido, pues su estancia se anunciaba larga y no quería dejarle solo tanto tiempo, pues además se sentían muy a gusto juntos.

Como no pudieron llevarse las cosas pacíficamente, como pretendía Felipe II, por la obstinación de Don Antonio, se optó por la vía militar. Concentró un ejército considerable, poniendo al frente del mismo al duque de Alba, don Fernando Álvarez de Toledo, con mando sobre las tropas de tierra y al marqués de Santa Cruz, don Álvaro de Bazán, al frente de la Armada española. En ese momento eran los militares más prestigiosos y más eficaces del reino, y como se confirmó a hora de la verdad, el 30 de agosto, cuando se alzaron con la victoria a las puertas de Lisboa, en la conocida como Batalla de Alcántara, por un riachuelo de dicho nombre, tributario del Tajo, a las puertas mismas de la gran urbe atlántica. El ejército del Prior de Crato reclutó un ejército numeroso, pero sin la experiencia ni el armamento ni con jefes militares de la talla de los de la parte contraria.

Con esta derrota se consolidó definitivamente el poder castellano en Portugal. El duque de Alba, en nombre del rey entró en Lisboa y proclamó rey de Portugal a Felipe II. Pero éste retrasó su solemne entrada, por estar afectado de la peste de gripe que por entonces asolaba el país, y que en un momento dado se pensó que el rey no iba a superar. Por fin salió indemne del trance pero no así la reina, que en pocos días falleció. Contaba la reina sólo 31 años.

Hemos dejado a Cervantes recién llegado a Valencia. Ya conoció en Argel el triunfo de la causa de Felipe II, pues sabemos la información privilegiada que tenía nuestro escritor, debido a sus contactos con mercaderes y otras personalidades que vivían o visitaban Argel. No sabemos si también conocería 
la grave enfermedad que había superado el monarca. Quizá llegó a Valencia con tiempo muy ajustado para asistir a un Te Deum de acción de gracias que se cantó en la catedral para celebrar la recuperación de su salud, según ordenaron las autoridades del Consell Municipal valenciano, después de recibir una carta del monarca, fechada en Badajoz el 15 de octubre ${ }^{43}$. La misiva se recibió el día 28 y se mandó que el 30 del mismo mes se celebrase un Te Deum de acción de gracias.

Pero apenas llevaba Cervantes semana y media en la ciudad de Valencia, llegó la noticia de la inesperada muerte de la reina Doña Ana, madre del futuro Felipe III, y de otros hijos más. La muerte había ocurrido el día 26 de octubre, a las cinco de la mañana, cuando Cervantes se hallaba navegando desde Argel - de donde había salido el día 24- rumbo a Denia. La noticia llegó a Valencia el día 12 de noviembre y de inmediato las autoridades civiles y eclesiásticas se emplearon a fondo para hacer unas exequias reales de gran pompa y solemnidad.

El día 13 por la noche Cervantes y sus amigos pudieron contemplar el solemne pregón que se hizo por las calles y plazas de la ciudad, anunciando para el 22 de noviembre la celebración de las exequias reales. Se declaraba día de fiesta, con el cierre obligatorio de oficinas, tiendas y mercados y dando detalles de cómo debían ir vestidos las autoridades y altos funcionarios, conforme al ceremonial establecido para estas ocasiones. El lugar sería la catedral, donde debían concurrir en procesión todas las parroquias y conventos a cruz alzada, seguida por el séquito de sus párrocos y beneficiados. Algo parecido debían hacer todos los conventos. El sonido de las numerosas campanas darían en su momento el tono fúnebre del acontecimiento. El toque de atención más llamativo lo daría el túmulo erigido dentro de la iglesia metropolitana cubierto de brocados, cartelas, jeroglíficos, versos funerarios, tan del gusto de esta época barroca.

Pero a consecuencia de unas innovaciones en el protocolo que pretendió hacer el virrey, referentes al puesto que debían ocupar los Jurados municipales en la ceremonia, hubo protestas por parte del Ayuntamiento y se aplazó la ceremonia hasta que resolviese esas diferencias el monarca. Salió de inmediato una embajada para resolver el conflicto, que resultó favorable al Ayuntamiento. La respuesta llegó el 10 de diciembre y se fijó para el 16 la ceremonia de las exequias reales, que fueron presididas por el virrey y oficiadas por el arzobispo, el Patriarca Juan de Ribera. pero Cervantes ya no estaba en Valencia.

Ésta hubiese sido la primera gran fiesta religiosa a la que hubiese asistido nuestro escritor desde que fue capturado en la galera Sol en 1575. Aún así no se le apartaba el recuerdo del triste final de la reina pues todos los días mientras duró la espera de la respuesta, los toques fúnebres de las campanas recordaban a los habitantes de la ciudad tres veces al día: al alba, a mediodía y al anochecer, el fallecimiento de la soberana. Todo ello sirvió a Cervavntes para recordar que en 1568, en Madrid, siendo alumno del Estudio de la Villa,

43. AMV: Manuals de Consells, A-105, f. 235rv. 
asistió a otra ceremonia similar con acasión de los funerales de Doña Isabel de Valois, la tercera esposa de Felipe II. La cual había fallecido el 3 de octubre de sobreparto y fue enterrada al día siguiente en las Descalzas Reales, celebrándose unos solemnes funerales el día 18. El Ayuntamiento de Madrid encargó a Juan López de Hoyos se ocupase de la parte artística del acontecimiento como composición de poesías, cartelas, jeroglíficos etc. además de relatar posteriormente en un libro la efemérides. En esta labor le ayudaron algunos de sus alumnos más aventajados, entre los que se hallaba Miguel de Cervantes, estudiante del Estudio de la Villa, cuyo director era el mencionado López de Hoyos. Cervantes contaba por entonces 21 años. Compuso para la ocasión cuatro poesías ${ }^{44}$, que fueron las primeras obras suyas dadas a la imprenta ${ }^{45}$. Se delata ya, a tan temprana edad un poeta fino y curtido en toda clase de composiciones poéticas ${ }^{46}$.

Poco tiempo después de la ceremonia tuvo que salir nuestro escritor huyendo de la justicia y ahora que regresa a España, al cabo de doce años, se encuentra con una ceremonia similar en Valencia, para honrar la memoria de la cuarta mujer de Felipe II, la que gobernó España durante todos los años de su ausencia del solar patrio. Sin duda no dejó pasar la ocasión para dedicarle alguna composición poética, aunque no pudo asistir finalmente a la celebración de sus exequias. La poesía, que siempre practicó a lo largo de su vida, era por estos años el único género literario que cultivaba. Además conviene recordar que años más tarde, en 1598, cuando fallece Felipe II, Cervantes se encontraba en Sevilla, e igualmente en su catedral se organizaron las exequias del gran monarca, y como no podía ser menos le dedicó sus poesías de rigor. Además de coplas reales en esta ocasión compuso y recitó públicamente una pieza que figura en las antologías de las mejores poesías en castellano. Se trata del famoso soneto con estrambote: Al túmulo del rey Felipe en Sevilla («Voto a Dios, que me espanta esta grandeza... »).

\section{Fin de la estancia de Cervantes en Valencia y salida para Madrid}

Pasado un mes largo en Valencia en compañía de sus dos buenos amigos Benavides y Chaves, cumplidos los trámites legales acostumbrados para hacer

44. Dos coplas castellanas, una en quintillas y la otra en redondillas; un soneto a modo de epitafio y una elegía.

45. La obra se imprimió al año siguiente y llevaba un largo título que resumido dice así: Historia y relación verdadera de la enfermedad, felicísimo tránsito y suntuosas exequias... de la reina Doña Isabel de Valois. Con los sermones, letras y epitafios a su túmulo... Madrid: Casa de Pierres Cosin, 1569.

46. No fueron éstas las primeras poesías salidas de su ingenio, pues el año anterior compuso un soneto dedicado al nacimiento de la segunda hija de Isabel de Valois, Catalina Micaela, y ese mismo año cuando fallece el Príncipe Don Carlos, también bajo la dirección de su maestro Juan López de Hoyos compuso varias composiciones poéticas con motivo de sus honras fúnebres, aunque esta vez no se editaron. 
frente a las deudas contraídas con los mercaderes valencianos, llegó la hora de la despedida que fue sin duda muy sentida dada la intensidad que alcanzó su convivencia a lo largo de tres meses, primero en Argel y luego en Valencia, en los que el noble andaluz corrió con los gastos de mantenimiento.

Don Diego de Benavides tomó el camino de Andalucía para visitar a sus padres ${ }^{47}$ y Cervantes emprendió la ruta de Madrid. Pero no iba solo, pues le acompañaba su otro amigo inseparable ya desde los días de su cautiverio, Rodrigo de Chaves ${ }^{48}$. Cervantes le vio por primera vez cuando llegó a Argel bogando en las galeras de Hazán Bajá, cuando vino éste como rey a dicha ciudad. Pronto intimaron y fue su confidente y su ayudante en la frustrada cuarta intentona de fuga. Chaves además testificó a favor de su amigo en el famoso Informe de Argel.

A Madrid debieron llegar a mediados de diciembre y cuatro días más tarde, el día 18, se presentó Rodrigo Chaves ante el notario Rodrigo de Vera y testificó lo que sabía del coste del rescate de Cervantes y las deudas pendientes que había contraído con los trinitarios y con mercaderes valencianos, que ya conocemos $^{49}$. Al día siguiente es el propio Cervantes el que testificó ante el mismo notario a favor de Chaves, y cuenta lo que ya hemos dicho sobre el cautiverio de seis años que había sufrido en Constantinopla y Argel, precio de su rescate y el alcance de sus deudas contraídas con el padre Gil y con algunos mercaderes valencianos. Ambos testimonios, el de Cervantes y el de Rodrigo de Chaves se escrituraron para tratar de conseguir alguna ayuda de los organismos oficiales. Desconocemos si tuvieron efecto práctico o sólo fue papel mojado, que es lo más probable. Lo más destacado de esta información es lo que comenta Cervantes en un momento de la misma: "vinieron juntos en un baxel hasta Denia y le ha contratado el tiempo que ha estado cautivo y después acá... $\rangle^{50}$, lo cual parece indicar que aparte de la amistad que tenían Cervantes se sirvió de él en ciertas faenas que no podía realizar debido a su manquedad. Sabemos también que le sirvió muy eficazmente en Argel durante

47. No sabemos si se volverían a encontrar en otra ocasión, pues sus destinos fueron muy diferentes. Don Diego volvería a servir en la milicia, donde pronto alcanzaría puestos de mando, dados sus antecedentes y el buen estado físico que tenía a pesar del cautiverio. Cuando Cervantes pasó una temporada entre Jaén, Úbeda y Baeza, durante los meses abril a octubre de 1591 ocupado en recaudar impuestos, don Diego estaría en cualquier lugar del imperio español. Con los que sí se entrevistaría Cervantes sería con los padres de don Diego, don Flores de Benavides y doña Inés de Peralta, que al menos le indicarían dónde se hallaba su hijo.

48. Por su acta de rescate sabemos que nació en 1550, tres años después que Cervantes, en Badajoz y que cayó prisionero en la defensa del fuerte de Túnez el 14 de septiembre de 1574. Fue trasladado como esclavo a Constantinopla y comprado por un tal Ebrahim, polvorista. Posteriormente fue vendido a Hazán Bajá y fue llevado con él a Argel cuando fue nombrado rey de dicha ciudad. Su rescate ocurrió el 27 de agosto de 1580, tres semanas antes que el de Cervantes. Dicho rescate costó 300 escudos de oro, y parte de dicha cantidad corrió a cargo de la limosna del Consejo de las Órdenes. Dejó debiendo unos 2.500 reales castellanos, una parte al padre Gil y otra a los mercaderes que la habían prestado ciertas cantidades para comer y vestirse.

49. Pérez Pastor, 1897, I, 65-67.

50. Pérez Pastor, 1897, I, 69-70. 
los preparativos de la cuarta fuga, en la transmisión de mensajes y porte de objetos de un lugar a otro.

Como colofón de esta estancia en Valencia y del impacto que causó en el escritor nada mejor que reproducir las propias palabras que dedicó Cervantes a Valencia en el último de sus libros, puesto en boca de unos cautivos que habían huido de los turcos y que al pasar cerca de Valencia, hablan de ella en estos términos: "Cerca de Valencia llegaron, en la que no quisieron entrar, por excusar las ocasiones de detenerse; pero no faltó quien les dijo la grandeza del sitio, la excelencia de sus moradores, la amenidad de sus contornos y finalmente, todo aquello que la hace hermosa y rica sobre todas las demás ciudades, no sólo de España, sino de toda Europa; y principalmente le alabaron la hermosura de sus mujeres y su extremada limpieza y graciosa lengua, con quien sólo la portuguesa puede competir en ser dulce y agradable ${ }^{51}$.

\section{LA REDENCIÓN DE 1583}

Es la mejor documentada de las expediciones redentoras del siglo XVI y sus fuentes nos aportan mucha información sobre la participación y relaciones de los mercaderes valencianos y el padre comisario de la misma, que en este año se daba la circunstancia de ser de nuevo el padre Juan Gil, el redentor de Cervantes, quien capitaneaba la expedición, al igual que la anterior de 1580. De ella nos han llegado dos fuentes de primer orden: el Libro de la Redención de la Orden de la Trinidad de $1583^{52}$, y el Protocolo notarial de Felipe Ayerbe de dicho año ${ }^{53}$, los cuales se complementan perfectamente. La primera fuente ya era conocida desde hace mucho tiempo por la crítica cervantina, la cual nos informa principalmente de las actividades del padre Juan Gil y de sus ayudantes. Pero los historiadores han pasado por alto las referencias que se hacen en el manuscrito a Juan Estéfano y Francisco Sasso y a otros mercaderes valencianos que ahora sacamos a la luz. Lo más novedoso son los Protocolos de Felipe Ayerbe, totalmente desconocidos y que refieren muchas de las actividades de dichos mercaderes desplegadas en las misiones de 1583 y 1587, y especialmente en ésta de 1583 que ahora tratamos.

La preparación de la mencionada expedición redentora de 1583 resultó ardua, y se aplazó varias veces debido a los continuos achaques del redentor, el padre Juan $\mathrm{Gil}^{54}$, afectado por prolongados episodios de fiebres tercianas. Apenas regresado a Madrid, después de los diez meses agotadores que pasó

51. Cervantes, 2004: cap. VII.

52. AHN: Códices, núm. 119.

53. ARV: Protocolos, núm. 154.

54. La biografía más completa del P. Gil sigue siendo la del padre Domingo de la Asunción: Cervantes y la Orden Trinitaria, (Madrid, 1917), que necesita ser actualizada y corregida en algunas de sus afirmaciones, hoy superadas por la reciente historiografía. 
en Argel, tuvo que emprender un penoso viaje a Lisboa, reclamado por Felipe II, donde se hallaba por entonces preparando la ceremonia de la toma de posesión del reino luso recientemente incorporado a la corona de España, tras haber superado una grave enfermedad y llorar la muerte de su esposa doña Ana de Austria. Apenas llegado a Lisboa el padre Gil a comienzos de septiembre de 1581 cayó gravemente enfermo y no pudo presentarse ante Felipe II hasta el 7 de octubre.

¿Qué quería Felipe II del padre Gil para reclamarle tan insistentemente, estando tan ocupado en asuntos políticos de gran calado? Deseaba que emprendiese de nuevo un viaje de redención a Argel, cuando apenas había rematado el anterior. El recuerdo de doña Ana de Austria era el motivo que le movía a ello, pues en una de las cláusulas testamentarias había reservado una elevada suma de dinero para dicha empresa y quería cumplir el deseo de la difunta lo antes posible. El Memorial que le presentó el padre Gil insistía en que era necesario habilitar cantidades de dinero proporcionadas por organismos oficiales pues las reservas de la limosna general de los particulares y las ofrendas de los monasterios de los trinitarios y de asociaciones piadosas estaban agotadas por los gastos de la expedición anterior y no habían tenido tiempo para hacer caja. El soberano accedió a ello y empezaron los trámites oficiales y el 30 de marzo de 1582 se hizo pública oficialmente la nueva expedición redentora.

De nuevo se nombró al P. Gil comisario de la misma y se le puso de ayudante al padre Francisco Girón y se nombró a Pedro de Anaya y Zúñiga notario real de esta misión. Las primeras limosnas fueron las recibidas del propio monarca, que ascendieron a 3.000 ducados. El mismo día, 19 de julio de 1582, el comisario recibió $1.666,50$ ducados del legado de la reina doña Ana de Austria ${ }^{55}$. Sin pérdida de tiempo comenzaron los largos viajes a través de las dos Castillas y Andalucía con el fin de recaudar las limosnas reservadas para este fin, depositadas fundamentalmente en los monasterios trinitarios, de acuerdo al modelo seguido en la de 1580. La preparación de este viaje resultó más lenta de lo previsto pues el responsable principal, el de más edad y deteriorado físicamente de todos cayó varias veces enfermo y sufrió varios accidentes. Su compañero, el padre Francisco Girón, también enfermó y renunció en un momento dado a la misión y hubo que buscar a última hora a otro compañero, el P. José Fornario. Lo más llamativo fue el cambio de escribanos reales, pues tres de ellos sucesivamente renunciaron a un cargo bien remunerado, hasta que a última hora llegó uno de Aranda de Duero, Francisco Martínez ${ }^{56}$, que será quien acompañe a los redentores a la capital

55. AHN: Códices, núm. 119, f.15v. La reina había dejado una manda de 3.333 ducados para la redención de cristianos retenidos en varias ciudades del norte de África. La mitad de ellos, 1.666,50 se destinaron a esta nueva redención de Argel.

56. El primer notario nombrado por el Consejo Real fue Pedro de Anaya y Zúñiga el 23-3-1582), que ya le había acompañado en la redención de 1580. Al renunciar al cargo le sustituyó Juan Carvajal, el 2-7-1582, que también renunció por enfermedad u otras causas que desconocemos y es cuando fue nombrado el tercer notario, llamado Rodrigo de Torres, el 4 de agosto de 1582. Pero no será finalmente 
argelina. Es decir que el más débil de todos los nombrados en un principio fue el único que finalmente emprendió el viaje a Argel, sin escudarse en el estado de salud tan precaria que tenía, como hicieron los otros. Es seguro que no estarían tan enfermos y debilitados como él. Todo un carácter.

Por fin llegó el padre Juan Gil a Valencia a finales de marzo, en pésimas condiciones de salud, exhausto por los sucesivos ataques de fiebres tercianas y otros contratiempos. No obstante sacó fuerzas para acudir en los meses de abril y parte de mayo a las «Montañas de Valencia», es decir a la zona de Alcoy y Cocentaina a comprar paños, así como a Segorbe. Completó la compra masiva de paños en la propia ciudad del Turia, donde además los envió a las tintorerías para ser teñidos de color púrpura, verde, rojo, etc. que luego vendería a altos precios en Argel, siempre con el objetivo de dar libertad al mayor número posible de cristianos esclavizados.

\section{Contrato de fletamento de la saetía «Virgen de la Misericordia»}

Entre los preparativos de los viajes a Argel capitaneados por los padres trinitarios revestía singular importancia el alquiler o fletamento de una nave que normalmente era una saetía-, en la que transportar a África las mercancías adquiridas por los padres redentores, y que sirviera al mismo tiempo de pasaje a ellos y a los viajeros que les acompañaban, un grupo de entre siete y doce mercaderes valencianos, que también acudían con sus mercancías propias y los adjutorios de familias de cautivos. Además se comprometía a permanecer el tiempo necesario en el puerto de Argel hasta que acabados los recursos económicos llegase la hora de regresar a España con los cautivos rescatados a bordo. Este tipo de documentos es muy raro, tanto es así que recientemente José A. Martínez Torres ${ }^{57}$ ha dedicado una excelente monografía a este tema del rescate de cristianos y en un momento dado confiesa que después de haber escrutado infinidad de documentos en los archivos de Madrid y Simancas, y leído una abundante bibliografía especializada, no había dado con el texto de contrato alguno de medios de transporte, en las misiones redentoras, tanto por tierra como por $\operatorname{mar}^{58}$, a pesar de las constantes referencias que a ellos se hace en la documentación conservada.

El tal documento se denomina en los protocolos notariales «Carta de fletamento», que en realidad es un contrato de arrendamiento, fechado en Valencia el 14 de mayo de 1583 y firmado entre Francisco Pau, patrón del navío Virgen

quien vaya a Argel como notario sino que ya en el último momento, poco antes de embarcarse la expedición, por enfermedad de Rodrigo de Torres fue nombrado Juan Martínez, de Aranda de Duero.

57. Martínez Torres (2004).

58. Martínez Torres (2004: 110): "No disponemos de los contratos que realizaron los redentores y los propietarios de los distintos medios de transporte tomados en Castilla, Andalucía, el Levante español y el Magreb...". 
de la Misericordia y San Telmo, mercader de Vinaroz, y el padre Juan Gil, procurador general de la orden trinitaria y redentor de cautivos, para dirigirse a Argel al objeto de liberar el mayor número posible de cristianos caídos en poder de los turcos en acciones bélicas o de piratería. Se llevó a cabo ante el notario Felipe Ayerbe y actualmente se halla depositado en el Archivo del Reino de Valencia ${ }^{59}$.

Se conocía ya el nombre del patrón y el de la nave, así como la cantidad abonada por el arrendamiento, pero no el texto del documento en cuestión, pues en el Libro de la Redención de Cautivos de Argel de $1583^{60}$, que contiene muchos documentos oficiales del rey y de los organismos administrativos competentes, no se hizo copia del mismo.

Comienzan las estipulaciones declarando el patrón que en el momento de zarpar la embarcación para emprender el viaje estará: «mi nave bien amarinada $^{61}$ y exarciada ${ }^{62}$ y bien stanca ${ }^{63}$ de cubierta, quilla y costado, apta y suficiente para el viage...» y se obliga a recibir en ella todas las mercancías ${ }^{64}$ que le entregue el arrendatario. Se compromete además a tenerla lista para hacerse a la mar el 10 de junio y el precio del flete de la nave se fija en 107 libras valencianas mensuales. Como mínimo se exige el pago de dos meses, aunque el viaje durase menos y si se prolongase por más tiempo se pagará en proporción el tiempo transcurrido de acuerdo con la tarifa mensual acordada. Incluso se precisan los términos de pago: la primera entrega se hará antes de salir del puerto de Valencia, la segunda una vez llegados a Argel y si se empleare más tiempo el finiquito se hará en Valencia, una vez regresados del viaje.

Si por algún motivo el navío no estuviese a punto en la fecha convenida el arrendatario puede alquilar otra embarcación obligándose el arrendador a pagarle la cantidad que excediere en el nuevo arrendamiento. El P. Gil debe asumir además los gastos del piloto de la nave. Como en el contrato se mencionan los marineros pero no su salario, debemos colegir que corría a cargo del patrón. Sin embargo el religioso debía hacerse cargo del pago de los impuestos y derechos de entrada, estancia y salida de los puertos ${ }^{65}$.

En una breve cláusula el padre Juan Gil «redemptor de cautivos nombrado por $\mathrm{Su}$ Magestad» ${ }^{66}$, acepta las condiciones del fletamento impuestas por el patrón del navío y se compromete a pagar el flete señalado y los impuestos que le carguen las autoridades argelinas.

59. ARV: Protocolos, núm. 154, ff. 214r-218v. Ver su texto en Apéndice documental, núm. 4.

60. AHN: Clero, Códices (Libro de la Redención de Cautivos de la Sma. Trinidad, año 1583).

61. Dotada con personal que la ha de tripular.

62. Aparejada.

63. Dividida en varias secciones, para dividir los lugares destinados a las mercancías, al personal, etc.

64. "todas las ropas, mercaderías e cosas que me daréis", todo ello debidamente inventariado por las "póliças de cargaçón”.

65. Por otros documentos sabemos que la tripulación de una nave de estas características estaba formada por cinco o seis personas.

66. En realidad era nombrado, como es lógico, por los superiores de la Orden de la Trinidad, el rey no hacía otra cosa que sancionar dicho nombramiento. 
La escritura se firmó en Valencia el 14 de mayo de 1583, como ya hemos dicho, algo más de un mes antes de su salida en dirección a Argel. Aquí nos llega la primera sorpresa. En todo documento notarial se necesita la presencia de dos o más testigos en el momento de la firma del mismo para que sea válido. Aquí aparecen dos, los cuales eran mercaderes y naturales de Ragusa ${ }^{67}$ : Juan Estéfano y Andrea Trentig, que por entonces residían en Valencia. Del primero de ellos, amigo especial de Cervantes, ya hemos hablado detalladamente en un parágrafo anterior. Del segundo, natural también de Ragusa y amigo a su vez de Estéfano, conocemos menos cosas.

Sin duda no se encontraron en la notaría Juan Estéfano y el padre Juan Gil por casualidad, sino que aquél le había acompañado a la notaría para escriturar el fletamento de la saetía de Francisco Pau, por ser allí donde Estéfano acudía siempre que sus negocios requerían la presencia de un notario y el aprecio que se habían tomado, unidos los dos en su amistad particular con Cervantes. El documento de fletamento o de alquiler de la saetía Virgen de la Misericordia y San Telmo se firmó ante el notario Felipe Ayerbe, importante profesional de la época, especializado en escrituras de tipo mercantil. A su oficina acudían algunos amigos de Cervantes que conoció en Argel y en Valencia -fuesen valencianos o no- como el padre Juan Gil, Juan Estefano, Francisco Sasso y Andrea Trentig, cuando tenían que registrar algún documento de tipo comercial o personal.

En los documentos notariales manejados en los que se cita la embarcación Virgen de la Misericordia y de San Telmo se le aplica el nombre genérico de nave y bajel. En realidad se trataba de una saetía, un tipo de nave muy común en esta época y muy utilizada para el transporte de mercancías desde la segunda mitad del siglo XVI y todo el XVII. Y así aparece denominada en el Libro de la redención de $1583^{68}$. La saetía en general usaba la vela latina y su tonelaje estaba en torno a los 1200/1500 quintales, gobernada por una dotación de entre 5 y 9 marineros. Servía tanto para el corso como para el transporte de mercancías y hasta de personas, como ocurrió con el transporte de moriscos y el de los cautivos rescatados de Argel que regresaban a la Península. Por esta época era el tipo de embarcación más contratada y utilizada en las expediciones redentoras que salían de Valencia rumbo a Argel.

El patrón de la saetía alquilada por el padre Juan Gil era Francisco Pau ${ }^{69}$, natural de Vinaroz, ciudad costera del Norte de Castellón, que contaba con un puerto muy activo pues ocupaba un enclave estratégico entre Valencia, Cataluña y Aragón. El mediador entre el patrón y el padre Juan Gil fue con toda seguridad Francisco Sasso, mercader genovés, que residía en el propio Grao, que era y ejercía también de piloto y estaba al corriente en todo momento de las embarca-

67. Ragusa, actual Dubrovnik.

68. AHN: Clero, Códices, 119, ff. 36v. Libro de la Redención de Cautivos de la Sma. Trinidad): "Los mercaderes que se embarcaron en la ç [aetía] de la Redención..."

69. Otras veces aparece denominado Pao, e incluso Paulo y Pablo. 
ciones que se hallaban disponibles para ser alquiladas. Francisco Pau ofreció sus servicios al padre Juan Gil, a través de Francisco Sasso, aprovechando la ocasión de que por entonces tenía un hermano cautivo y quería rescatarlo a toda costa. Esto lo sabemos por el Libro de la Redención del año $1583^{70}$. Este hermano se llamaba Hipólito Pau ${ }^{71}$. Tenía 50 años. Cayó cautivo yendo en una nave de Livorno a Génova el 27 de setiembre de 1582. Estaba en poder del arráez Feru, un renegado genovés que operaba desde Argel. Su rescate fue bastante elevado pues costó 600 doblas $^{72}$, cuando la media era de 300 doblas, las cuales entregó su hermano al padre Juan Gil, que fue quien gestionó su libertad. Por lo tanto estuvo solamente en poder de los corsarios trece meses.

Hemos dado también con el contrato de la nave redentora de 1587. Aunque ya no entra en el espacio cronológico que nos hemos fijado es digno de traerse a cuento pues demuestra cómo la amistad y los negocios forjados entre ambas partes -el padre Gil y los mercaderes valencianos- se mantuvieron vivos durante muchos años, cuando ya le habían separado los superiores de la empresa por razones de salud. Son muchas las concomitancias de ambos contratos -el de 1583 y el de 1587- pues en ambos casos nos hallamos ante naves fletadas para ir a Argel en busca de cautivos y donde aparecen implicados los mismos personajes: el notario Felipe Ayerbe, Francisco Sasso como mediador y los padres trinitarios, sucesores del padre Juan Gil, como arrendadores.

Esta vez tuvieron serias dificultades para encontrar un navío disponible para el viaje. No se hallaba ninguno en el puerto de Valencia debido a que todos estaban ocupados en colaborar en la logística de la Armada Invencible -que por aquellos días estaba anclada en Lisboa a punto de zarpar rumbo a Inglaterra- en el transporte de suministros y soldados. Y además, cuando llegaron los redentores a Valencia, nuevos en el oficio, se encontraron con que su valedor en estos menesteres, Francisco Sasso, acababa de salir a Argel pilotando una saetía que había alquilado Alonso de Ribera, gentilhombre del Marqués de Villena, para rescatar a varios súbditos de su señorío ${ }^{73}$. Y como el tiempo apremiaba no tuvieron más remedio los padres trinitarios que ir a Alicante a alquilar un navío que estaba libre y dispuesto para el viaje proyectado. Su patrón era el catalán Lluís Monet y la nave se rotulaba Santa María y San Telmo. Aprovechándose de la escasez de barcos de alquiler que había en el mercado exigió a los religiosos la desorbitada cantidad de 425 libras valencianas de alquiler mensual, es decir cuatro veces más que el precio normal del mercado. El contrato se firmó aproximadamente el 15 de octubre.

70. AHN, Clero, Códices, 119, f.38v (Libro de la Redención de Cautivos de la Sma. Trinidad)

71. También aparece en la documentación como Hipólito Pao o Paulo

72. "En 9 de agosto [1583] su Paternidad recibió de Francisco Pao 500 doblas para el rescate de su hermano Ypólito Pao, natural de Vinarós en el Reino de Valencia...". AHN: Clero, Códices, f. 112v. (Libro de la Redención de Cautivos de la Sma. Trinidad). Las 100 restantes debieron ser abonadas de la Limosna General.

73. Este protocolo nos ofrece también el texto de este contrato, en ARV: Protocolos, núm. 55, ff. $531 \mathrm{v}-536 \mathrm{v}$. 
Cuando Francisco Sasso regresó de Argel a principios de noviembre y se enteró de las dificultades que habían tenido para encontrar una embarcación y sobre todo del precio tan elevado en que la habían contratado, se ocupó de ir personalmente a Alicante a rescindir un contrato ${ }^{74}$ tan oneroso ${ }^{75}$. Además el genovés les buscó un nuevo barco, que era justamente el del patrón Juan Llombart ${ }^{76}$, francés de Six-Forns, en Provenza. Se trataba de la misma saetía que había pilotado y en la que acababa de llegar de Argel, rotulada con el nombre de Santa María Buenaventura y San Telmo, y fue fletada por un montante cuatro veces inferior a la del patrón catalán.

El contrato se firmó el 6 de noviembre de $1587^{77}$ por el precio de cien escudos de oro en oro al mes $^{78}$, equivalentes a 112 libras valencianas, más barato incluso que el fletamento de 1583. Curiosamente no aparece la cláusula referente al pago del piloto, pero sabemos con toda seguridad que corrió a cargo de los arrendadores pues tenemos un asiento que lo confirma ${ }^{79}$. El contrato es más largo que el de 1583, y se ve que se respiraba un ambiente menos seguro, debido a la guerra hispano-británica, en la que participó la Armada Invencible y por eso el patrón toma más precauciones ante el temor de robos y ataques imprevistos.

Estos contratos de fletamento tienen un interés especial pues nos ponen indirectamente en contacto con el que firmó el padre Juan Gil en 1580, que se puede dar por perdido. Mismo notario, mismos promotores, mismos o muy parecidos términos contractuales y mismos objetivos a cumplir: llevar un grupo de mercaderes valencianos y traer a un numeroso grupo de cautivos redimidos. Sólo hubo cambio de barco y de patrón, pero idéntico piloto. También cambiaron los redentores, los sucesores del padre Gil, no tan expertos como él y en circunstancias especiales. Pero allí estaban los mercaderes para echarles una mano. Y ya veremos que su ayuda se extendió a otros asuntos. Las figuras del padre Gil y de Miguel de Cervantes seguían estando presentes de alguna manera.

74. AHN: Clero, Códices, núm. 122, f. 267v. (Libro de la Redención de la Orden de la Sma. Trinidad).

75. No obstante no se libraron de tener que abonar 350 libras por el tiempo que había transcurrido desde el día de la firma. Aún así se ahorraron unos cientos de libras. El viaje como veremos duró tres meses y medio, lo que les hubiera costado 1459 libras.

76. No Juan Combrat, como dice PORRES (1997-1998: I, 327)

77. ARV: Protocolos, núm. 155, ff. 778r-782r.

78. El equivalente del escudo, moneda castellana, era de 22 sueldos y medio, es decir de 1,125 Libra valenciana.

79. Salario del Piloto: "En la dicha ciudad de Argel, este dicho día mes y año susodichos [4 julio 1588]... el dicho P. Presentado dio y pagó a Francisco Sasso, piloto 45 escudos de oro de a 400 maravedís, los cuales se le debían de su trabajo y pilotaje de los dos viajes que hizo de Argel a Valencia..." En: AHN: Clero, Códices: 122, f. 233v. (Libro de la Redención de la Orden de la Sma. Trinidad). 


\section{El padre Juan Gil y los mercaderes valencianos}

El día 15 de junio se procedió al embarque y evaluación de las mercaderías que salían para Argel, obviamente de aquellas que no estuviesen prohibidas por ley. Acudió el regente, en nombre del virrey, acompañado de una cohorte de escribanos, alguaciles, verguetas y estimadores para registrar y evaluar la hacienda que se iba acumulando en las bodegas de la embarcación.

Para no perder tiempo, al atardecer de ese mismo día, una vez terminados los trámites reglamentarios, se embarcaron en la saetía junto con los padres redentores y el patrón de la nave Francisco Pau, catorce mercaderes valen$\operatorname{cianos}^{80}$, entre ellos los dos más conocidos por nosotros, Francisco Sasso y Juan Estéfano, que se ocupaban, además de otras actividades comerciales al uso, la de gestionar los rescates de cautivos de acuerdo con sus familiares. Además Francisco Sasso, fue contratado como piloto, por lo cual recibió su salario de manos del padre Juan Gil, según se recoge en el contrato de fletamento y en las cuentas del Libro de la redención. Los demás mercaderes embarcaron mercancías para venderlas en Argel. El padre Juan Gil les cobró a su vez sus derechos, consistentes en el ocho por ciento del valor tasado por expertos de las mercancías que llevaron a Argel, por usar el barco que había alquilado, consistentes mayormente en paños, bonetes y cardas ${ }^{81}$ para trabajar la lana. Además estos mercaderes tuvieron que pagar otras 292 doblas argelinas, equivalentes a 1825 reales castellanos por el nólit o flete de sus personas y mercancías ${ }^{82}$.

Estas cantidades las empleó luego el padre Gil para pagar impuestos y rescatar cautivos, es decir que ambas partes se beneficiaban. Se patentiza una vez más cómo las relaciones comerciales nunca se interrumpieron entre los imperios Español y Otomano, a pesar de su enemistad oficial, y así mismo se pone de manifiesto la buena sintonía que existía entre las órdenes redentoras y los mercaderes en cuanto a la gestión de la liberación de los cautivos cristianos.

La saetía salió por fin del puerto de Valencia el 16 de junio, al amanecer, tal como recoge el Libro de la Redención de $1583^{83}$. Una prueba evidente del aprecio que sentía el padre Juan Gil por los dos mercaderes amigos de Cervantes es el detalle que tuvo con ellos, al mandar poner sus nombres, en calidad de testigos, en el acta de salida de la saetía del puerto de Valencia, al amanecer del día 16 de junio, distinguiendo con ello a Francisco Sasso y Juan

80. Fueron éstos: Vicente Piló, Francisco de Requena, Pedro Peregrín, Juan Estéfano, Antonio Grosso, Gil Cervera Salas, Francisco Ramón, Bartolomé Xarque, Bartolomé Esteban, Vicente Geroboa, Pedro Domingo, Guillem Manuel y Francisco Sasso, que además sabemos por otras fuentes que fue el piloto de la nave.

81. Juan Estéfano llevaba para negociar, además de cantidades en metálico, 29 paños y 580 pares de cardas para trabajar la lana.

82. AHN: Clero, Códices, núm. 119, f. $38 \mathrm{v}$

83. AHN: Clero, Códices, núm. 119, f. 81r. Ver el documento en Apéndice Documental, núm. 5. 
Estéfano entre los catorce mercaderes valencianos que también acompañaban al padre Gil en la expedición. La nave siguió rumbo sur, haciendo una corta escalada en Denia.

La saetía Virgen de la Misericordia llegó a Argel el 25 de junio. Debió de ser por la mañana temprano pues hubo tiempo ese mismo día para que realizase una visita de inspección al navío el Justicia Mayor del rey y un representante de los jenízaros para trasladar a continuación todas las mercancías a la Casa del Rey, como era costumbre. Al día siguiente, que era domingo, se presentó en persona el rey de Argel, el cruel y avariento Hazán Bajá, acompañado de su alamín y otros oficiales y justicias de Argel sin que faltasen los jenízaros más representativos ${ }^{84}$. Todos ellos, en presencia del notario de la redención y del padre Juan Gil, asistieron a la evaluación de los mercadurías llegadas de Valencia, que en síntesis se resumían en paños de diversas medidas y teñidos de varios colores, mantas grandes y pequeñas, comprados todos ellos en la zona de Valencia; 320 docenas de bonetes toledanos y 54 onzas de aljófar de Sevilla todo lo cual fue evaluado en 22.767 doblas. El rey de Argel percibió 2.276 doblas, es decir el 10\% del total. También se llevaron su parte el alamín, que se tuvo que contentar con el 1,5\%, e igualmente percibieron una porción del botín los jenízaros, el capitán general de Argel, los chauces y los guardas ${ }^{85}$. $\mathrm{Ni}$ que decir tiene que el rey eligió las mejores mercancías que pagó con el dicho $10 \%$ de los derechos que por ley le pertenecían además de recibir otros regalos del padre Juan Gil como bonetes, dulces, frutas confitadas, etc.

El rey de Argel le vendió quince cautivos que tenía en propiedad. No cumplió la palabra dada a fray Juan Gil en el sentido de que los cautivos a liberar fuesen de Castilla, que es de donde procedían los adjutorios y limosnas, logrando colocar entre los liberados a cinco personas de la Corona de Aragón. Especial comentario merece la redención de don Jerónimo de Palafox, caído prisionero el 9 de abril de 1575 a los 23 años de edad, cuando se dirigía en una galeota desde Sicilia a Nápoles en servicio del rey, lo que quiere decir que estuvo cautivo durante ocho largos años. Era natural de Ariza y pertenecía a una familia noble aragonesa. Estuvo a punto de ser liberado en 1580, cuando el padre Juan Gil le ofreció 500 escudos de oro que traía de España para su rescate $^{86}$. Pero el Bajá de Argel no cedió y no rebajó su pretensión de los 1000 escudos en que había valorado la libertad del noble aragonés.

84. AHN: Clero, Códices, núm. 119, ff. 81v-82r.: "En la ciudad de Argel, en 25 de junio, se llegó a la dicha ciudad e se visitó el navio en que íbamos por la Justicia Mayor del Rey y Xeníçaros, e se llevó la ropa e la demás hacienda en Casa del Rey, como es costumbre. Y luego, otro día siguiente, domingo a 26 de dicho mes, se hizo valuación de toda la dicha hacienda por ante mí, Juan Martínez, escribano de la Redención; el muy Rvdo. Padre fray Juan Gil, redentor de cautivos, ante Hazán Bajá, rey de Argel e su Alamín e Galifa e Xeniçaros y otras Justicias y Oficiales de Argel..."

85. AHN: Clero, Códices, núm. 119, ff. 81v-83v.

86. En efecto el padre Gil recibió el 5 de mayo de 1580, en Valencia, 5.130 reales castellanos de parte de los familiares de Don Jerónimo de Palafox. Pero no sirvieron para nada pues el rey exigió 1.000 escudos de oro. Hubo que esperar a la expedición de 1583 para su liberación. Ver AHN: Clero, Códices, núm. 118 , f. $38 \mathrm{v}$. 
Don Jerónimo de Palafox partió a Constantinopla en octubre de 1580 con su amo, Hazán Bajá, depuesto como rey de Argel. Regresó de nuevo a Argel con su amo, repuesto como soberano de dicha ciudad, merced a las elevadas cantidades que ofreció al Gran Turco, y donde se encontró de nuevo con el padre Gil en este segundo viaje que hacía de rescate en Argel. Esta vez aceptó la liberación de don Jerónimo de Palafox por sólo 600 escudos. El padre Gil no traía adjutorio para él, pero nuestros conocidos mercaderes valencianos y amigos de Cervantes, Francisco Sasso y Juan Estéfano estaban allí para ofrecérselo. Dichos mercaderes le proporcionaron de inmediato 500 escudos de oro $^{87}$ y el padre Juan Gil aplicó otros 100 escudos de la limosna general. Esta vez logró su libertad y por menos de lo que se le había exigido tres años antes ${ }^{88}$.

Una vez comenzado el período de la compra de cautivos, el 7 de julio Juan Estéfano entregó al padre Gil 250 escudos para rescatar a Juan Calamón, de Villagarcía ${ }^{89}$ y lo mismo hizo Francisco Sasso, el 20 de dicho mes, para liberar a Diego Díez Montañés ${ }^{90}$. En estos dos casos los adjutorios que traían los mercaderes no eran suficientes para cubrir el precio que exigían sus dueños y entonces el padre Gil cubría la diferencia echando mano al fondo de la limosna general. Siguiendo esta misma tónica, el 2 de agosto vemos a Juan Estéfano y Francisco Sasso entregando un adjutorio para la liberación del calabrés Lorenzo Osorio ${ }^{91}$. Y tres días más tarde se logró el rescate de dos cautivos catalanes, Juan Calvet, de Tossa de Mar y María de Candía, de Castellón de Ampurias ${ }^{92}$. En esta ocasión fue Francisco Sasso junto con Antonio Salas, mercader valenciano, quienes aportaron el dinero.

No acabaron aún de resolverse los encargos de los familiares que habían acudido a los mencionados Francisco Sasso y Juan Estéfano, y rozando ya el final de la expedición, el padre Gil dio con el paradero de algunos de ellos y gestionó el precio de su rescate con sus dueños. Francisco Sasso entregó al dicho Padre 400 doblas para conseguir la libertad de Juan Ruiz, de Caravaca ${ }^{93}$. Por su parte Juan Estéfano traía el encargo de liberar a Pedro de Atienza, natural de Murcia, y entregó al P. Gil 150 doblas que le habían adelantado sus familiares $^{94}$ y a Jerónimo Aragonés, oriundo de Cuenca, para quien le habían adelantado sus familiares 100 doblas. Y finalmente, el 19 de agosto, Francisco Sasso y Juan Estéfano, mancomunadamente, entregaron al P. Gil 100 doblas, con las que pudo rescatarse a Jorge Oliva, de Mallorca ${ }^{95}$.

87. AHN: Clero, Códices, núm. 118, f. 37r. Ver el documento en Apéndice documental, núm. 6.

88. Recordemos que entonces Hazán Bajá exigía 1000 escudos de oro por su liberación.

89. AHN: Clero, Códices, núm. 119, f. 37r.

90. AHN: Clero, Códices, núm. 119, f. $37 \mathrm{v}$.

91. AHN: Clero, Códices, núm. 119, f. 38r.

92. AHN: Clero, Códices, núm. 119, f. 38r.

93. AHN: Clero, Códices, núm. 119, f. 39r.

94. AHN: Clero, Códices, núm. 119, f. 39r.

95. AHN: Clero, Códices, núm. 119, f. 39v. 
La segunda fuente de información que tenemos sobre los amigos de Cervantes nos la proporciona el Protocolo de Felipe Ayerbe de 1583. En él no solo aparecen unos apuntes al respecto, como ocurre en el Libro de la Redención de dicho año, tal como acabamos de exponer, sino los documentos notariales en toda su extensión textual. En efecto, sabemos que Estéfano y Sasso, junto con otros mercaderes valencianos acompañaron al padre Juan Gil en su viaje de 1583 y colaboraron con el mismo religioso en la redención de varios cautivos, adelantando el importe de los rescates ${ }^{96}$.

Desde finales de marzo de 1582 en que se supo que iba a partir una expedición de rescate a Argel, hasta la salida de la saetía en junio de 1583, acudieron a Valencia -lugar de salida de la nave redentora- algunos familiares que tenían cautivos en Argel para hablar con los mercaderes que entendían en el asunto de la liberación de cautivos. Pero sólo nos han llegado algunos de estos encargos, pues el protocolo de 1582 se ha perdido.

Así pues tenemos en primer lugar un grupo de escrituras notariales redactadas antes del viaje - de enero a junio de 1583- relacionadas principalmente con los tratos entre los familiares y los mercaderes a propósito de la redención de los cautivos y la forma y cantidad que podían adelantar o prometer. En segundo lugar nos encontramos con escrituras redactadas después del regreso de la expedición, donde se formalizaron con precisión las cantidades adelantadas por los mercaderes a los excautivos y la forma y tiempo en que iban a pagar las deudas contraídas con dichos mercaderes.

El primer documento con el que nos encontramos es una Carta de Obligación de Juan Ruiz de Chinchilla, vecino de Vera, quien se obliga a pagar a Francisco Sasso 331 doblas argelinas que le había adelantado por su rescate en Argel ${ }^{97}$. Todo indica que dicho rescate lo llevó a cabo el mercader genovés Francisco Sasso en uno de sus frecuentes viajes que hacía a Argel. Pudo haber sido hecho a finales de 1582 o muy a principios de 1583. Es un ejemplo de redención directa entre familiares y mercaderes, que se llevaban a cabo con normalidad durante los años que no había viaje de redención.

Dos meses más tarde el mismo mercader recibe de manos de Pedro de la Plaza Bravo, de Baza, 2.310 reales castellanos para que lleve a cabo la redención de su hermano Jorge ${ }^{98}$, cautivo por entonces en Argel, y dentro ya de la campaña del nuevo viaje a Argel del padre Juan Gil. Pocos días después, el 7 de abril, el mismo Sasso recibe de los familiares de Tomás Despiu, de Cartagena, 1694 reales y la promesa de otros 1650 si lleva a cabo su liberación ${ }^{99}$.

Aparece también un documento relacionado con otro personaje cervantino, el de Francisco de Aguiar, mercader portugués que ya por entonces se ocupaba de la redención de cautivos lusos y seguirá por muchos años en esa actividad,

96. AHN: Clero, Códices, núm. 119, ff. 37r-40r.

97. ARV: Protocolos, núm. 154, ff. 22r.-24v.

98. ARV: Protocolos, núm. 154, ff. 146r-147r. (29 marzo 1583).

99. ARV: Protocolos, núm. 154, ff. 160r-164v. (7 abril 1583). 
como vemos en varios documentos del Archivo del Reino de Valencia ${ }^{100}$. Por aquellos años las cárceles de Argel y los bancos de las galeras de los corsarios estaban atestados de portugueses caídos en poder de los musulmanes tras la derrota del ejército portugués de Don Sebastián en la batalla de Alcazarquivir (4 de agosto de 1578). Fue él quien en última instancia compró el privilegio otorgado por Felipe II a la madre de Cervantes doña Leonor de Cortinas para que pudiese llevar a Argel mercancías por valor de hasta 2.000 ducados, y con el beneficio de su venta pagar el rescate de su hijo. Como se deduce de este documento Francisco de Aguiar visitaba igualmente la notaría de los amigos de Cervantes. La pérdida de los protocolos de dicho notario nos ha privado también de saber los términos exactos en que se llevó a cabo la transacción de la venta de dicha licencia real. En este caso se trata de una carta de obligación que suscribió a su favor Pantaleón Gonzálbez, por valor de 94 escudos de oro, que le había prestado en Argel para su liberación ${ }^{101}$. Suena un tanto extraño el que por una parte Cervantes conociese y tuviese tan buenos amigos mercaderes en Valencia y que a la hora de la verdad ninguno de ellos se prestase a comprar la licencia dada por Felipe II a su madre para ayudarle a pagar su rescate y que tuviese que ser un portugués quien lo hiciese finalmente.

Los familiares de los cautivos acuden como última esperanza para rescatar a sus seres queridos a las personas que iban en el viaje de redención: unos tratan directamente con los trinitarios, como se ve en los Libros de Redención, otros lo hacen con los mercaderes que acompañan a dichos religiosos, e incluso tenemos el caso de unos amigos y familiares de Pedro del Rincón, vecino de Lorca «que está cautivo en poder de moros enemigos de nuestra santa fe católica», que acuden a Juan Martínez, el notario de Aranda nombrado por la Corona para que acompañase al padre Juan Gil. No adelantan cantidad alguna, sólo la promesa de que le abonarán el coste de la operación una vez llegue libre a Valencia. Pensaron que al estar tan cercano al padre Juan Gil sería más fácil lograr su empeño ${ }^{102}$.

Finalmente, pocos días antes de embarcarse, acudió de nuevo a la notaría Francisco Sasso para formalizar un documento de compromiso con los familiares de Hernando Navarro, natural de Lorca y cautivo en Argel, en la que se obligan a pagarle «incluso si muriese antes de llegar a tierra de cristianos» todo lo que costase la redención de dicho Hernando ${ }^{103}$. Esta vez sí que tuvo resultado positivo el rescate, pero en los demás casos que acabamos de enumerar y en los que se adelantaron cantidades para el rescate o se hicieron promesas de pago, no tuvieron un final feliz. Ni Juan Ruiz Chinchilla, Martín Despiu ni Pedro del Rincón lograron volver a su patria. Lo sabemos al examinar las listas de los cristianos rescatados en este viaje por una parte y

100. ARV: Real, Reg. 620, ff. 32bis-39v. Benítez (2008: 193-217).

101. ARV: Protocolos, núm. 154, ff. 26r-27v. (21 enero 1583).

102. ARV: Protocolos, núm. 154, ff. 246r-248r. (14 junio 1583).

103. ARV: Protocolos, núm. 154, ff. 248r.-250v. (14 junio 1583). 
los nombres de los cautivos por los que se ofrecieron cantidades en efectivo o promesas de pago de su importe si se consigue la redención. Sabemos que no siempre era fácil dar con el paradero de dichos cautivos, excepto si estaban detenidos en la cárcel o baño real, caso de Cervantes. Además muchos de ellos habían fallecido o apostatado y no deseaban volver a España por miedo a la Inquisición. También hay que tener en cuenta que los dueños de los cautivos les podían enviar a trabajar lejos de Argel o emplearlos en las galeotas dedicadas al corso, donde permanecían largos meses recorriendo el Mediterráneo en busca de presas, o bien se negaban a venderlos bajo ningún concepto o ponían precios prohibitivos.

Este segundo viaje del padre Juan Gil sólo duró dos meses largos, tiempo que resulta muy breve si lo comparamos con los diez que duró el anterior de 1580. Fue además menos complicado y de menos sufrimientos y escarnios para el padre Gil. El número de rescatados fue de 147, frente a los 187 de la anterior, pero teniendo en cuenta que duró menos de una cuarta parte de tiempo, el balance resultó muy positivo.

Una vez se agotaron los recursos económicos de las limosnas y adjutorios que pudieron allegar los trinitarios y agotada la esperanza de encontrar con vida o dar con el paradero de aquellos para los que se traían fondos para su rescate a través de los mercaderes se pensó regresar a Valencia. Zarparon efectivamente de Argel el día 24 de agosto, yendo a bordo de la saetía 102 cautivos pues los restantes ya habían salido a sus lugares de origen en otras embarcaciones. El 29 de agosto llegaron a Valencia, después de descansar un día en Denia. La procesión se efectuó, según el ritual acostumbrado el 30 de agosto.

Al día siguiente, y sin pérdida de tiempo, para que pudieran dirigirse a sus lugares de origen lo antes posible, aquellos excautivos que habían logrado su rescate merced a la ayuda económica de Juan Estéfano y Francisco Sasso, se presentaron en la oficina de Felipe Ayerbe para formalizar el pago de la deuda contraída con ellos. Cuatro de ellos fueron rescatados merced al adelanto de dinero ofrecido por Sasso y uno por Juan Estéfano.

El padre Juan Gil desapareció como comisario de los viajes de redención, una vez vuelto a casa en 1584. Pero las expediciones redentoras siguieron celebrándose con bastante frecuencia hasta el siglo XVIII, siguiendo las pautas marcadas por Felipe II y el padre Gil. Los mercaderes valencianos formaban parte importante del engranaje, como hemos visto y probado. En estas actividades se distinguieron Francisco Sasso y Juan Estéfano, colaboradores muy especiales del padre Gil, tal y como lo reconoció dicho padre en alguna ocasión. Mientras estos dos mercaderes estuvieron activos en Valencia, lo que ocurrió hasta principios del siglo XVII, a pesar de la desaparición personal del padre Gil en los viajes, continuaron colaborando con los padres trinitarios que fueron llegando en sustitución del venerable padre Juan Gil.

En el protocolo de Felipe de Ayerbe de este año se encuentran ejemplos de colaboración entre los redentores y los mercaderes valencianos. Así por ejemplo el ya mencionado Francisco Sasso, además de pilotar la saetía alqui- 
lada gracias a sus desvelos y titulada Santa María Buenaventura, participó con dichos religiosos en la redención de varios cautivos, los familiares de los cuales le habían confiado adjutorios. También sabemos que el dicho Juan Estéfano participó en la redención de varios cautivos ${ }^{104}$. E igualmente Andrea Trentig, paisano y amigo de Estéfano, que acudió a Argel en esta expedición llevaba adjutorios de familiares de cautivos ${ }^{105}$.

Esta colaboración la tenemos también documentada en la expedición redentora de 1591-1592, aunque en menor medida pues carecemos de la principal fuente, es decir, de los protocolos de Felipe Ayerbe. Aún así sabemos por el Libro de la Redención de 1591-92 $2^{106}$ que Juan Estéfano acompañó al comisario en esta ocasión, el padre Juan de Palacios, novato en estos menesteres, a Alcoy y Cocentaina a comprar paños, que una vez teñidos en Valencia se llevaron a Argel $^{107}$, según norma habitual ya comentada y que había sido establecida por el padre Juan Gil. Como de costumbre debieron acompañarlos en el viaje a Argel un grupo de mercaderes valencianos, entre ellos Francisco Sasso, que además era el piloto de la saetía.

Estos amigos del padre Gil y de Cervantes continuaron poniendo en práctica ese mismo proceder mientras siguieron activos en el comercio Valencia-Argel, es decir hasta finales del siglo XVI o comienzos del XVII, en que sus nombres desaparecen de la documentación.

Francisco Sasso, piloto y mercader (Génova, h. 1515 - Valencia, h. 1601)

Estamos ante un personaje curioso, totalmente desconocido por la crítica historiográfica. No figura en las listas que de vez en cuando aparecen en los estudios sobre mercaderes europeos establecidos en Valencia. Sólo he encontrado una referencia a su persona en un artículo, en el que se analiza la compra del privilegio otorgado por Felipe II a doña Leonor de Cortinas por parte del comerciante portugués Francisco de Aguiar, donde además se le clasifica como un mercader marsellés, afincado en Valencia ${ }^{108}$, pero como vemos repetidamente en la documentación era genovés.

Sasso fue un mercader bastante importante en su época y que desarrolló múltiples y variadas actividades. Trató a Cervantes en Argel y en Valencia y colaboró

104. ARV: Protocolos, núm. 155, ff. 531v-536v (Cautivo: Andrea Zelenco); ff. 210-213 (Cautivos: Fernando Martínez y Miguel Córdoba)

105. ARV: Protocolos, núm. 155, ff. 208-210 (Cautivo: Tomás Saura)

106. AHN: Códices, 121, f. 98r.

107. Se conserva el recibo de pago que recibió Juan Estéfano.[Gasto que se hizo en ir de Valencia a las Montañas, a comprar la ropa]. "En la ciudad de Valencia, a 10 días del mes de octubre de 1591, el P. fray Juan de Palacios dijo haber pagado a Juan Estéfano, vecino de la dicha ciudad 156 reales , que valen 5.100 maravedís que el susodicho gastó en ir a las Montañas de Alcoy con el susodicho Padre Fray Juan de Palacios a comprar ropa".

108. Benítez (2008). 
con el padre Juan Gil y sus sucesores a lo largo de todos los viajes que llevaron a cabo a Argel para redimir cautivos cristianos entre 1580 y 1595 . Además de mercader fue piloto de naves y patrón o dueño de una embarcación propia. Gracias a la variada documentación -inédita en la mayoría de los casos- hemos podido trazar los datos esenciales de su biografía que se extiende a lo largo de los dos últimos tercios del siglo XVI y llega justo a comienzos del siglo XVII.

Sabemos por propia confesión que era natural de Génova ${ }^{109}$. Debió de nacer hacia $1515^{110}$. Desde muy joven estuvo implicado en la vida marítima y comercial, como buen genovés que era, teniendo una inclinación especial hacia el manejo y conducción de las naves y ya muy tempranamente se dedicó al pilotaje de las mismas, actividad que ejerció hasta el final de su vida activa. Él mismo lo afirma ante un juez: «Diu [Francisco Sasso] que és mariner e acostuma de anar com a pilot a moltes e diverses parts de levant e ponent» es decir que recorrió el Mediterráneo en todas sus direcciones $\mathrm{y}$ en incontables ocasiones.

En un momento dado fijó su residencia en Valencia, pero no en el centro de la ciudad, donde se hallaban instalados la mayoría de los mercaderes, sino en el Grao, un pequeño poblado bien fortificado, al pie mismo del puerto. Nada extraño si pensamos que por entonces su principal profesión era la de piloto, y aquél era el lugar más adecuado para estar en contacto directo con los barcos y sus patronos. Esta residencia la mantendrá hasta el final de sus días. La fecha exacta de su llegada a Valencia no aparece en los documentos consultados.

Por los libros de Peaje de Mar sabemos que ocurrió en torno a 1534, pues en ese año ya le vemos comerciar en Argel, adonde llegaría pilotando un barco. Desde allí importó productos a Valencia como los otros mercaderes que acudieron con él a dicha ciudad. Y ya desde entonces alternó ambas actividades: la de mercader y la de piloto, y con el tiempo añadió la de patrón, como propietario de un barco, que a su vez alquilaba a otros mercaderes, entidades o particulares que lo necesitasen para sus negocios o necesidades y para cuya explotación le dotó de piloto y marinería.

Esta triple actividad marinera y mercantil la describe perfectamente Mariano Asensi, un corredor de oreja, que en 1581 testificó a su favor en el pleito que mantenía con Domingo Vázquez:

... el dit Sasso anava a Argel per patró, y té entés que lo dit Francisco Sasso és anat y ha fet diversos viatges a la dita ciutat de Alger y altres en ponent, com a patró algunes vegades del vexell que anava, y altres vegades com a pilot ... y haver-lo vist algunes vegades partir, nomenant-lo algunes vegades pilot y altres patró dels vexells en que anava ${ }^{111}$.

109. ARV: Real Cancillería, núm. 620, f. 18v.; ARV: Real Audiencia, Procesos, $2^{a}$ Parte, Letra D, exp. 99.: "Diu lo dit Francisco Sasso és de nació genovés e viu e habita en lo loch de Guerau (=Grao) de la present ciutat de València”.

110. En el siglo XVI para ejercer la profesión de Mercader había que tener al menos veinte años y sabemos que en 1534 ya ejercía como tal comerciando entre Argel y Valencia.

111. ARV: Real Cancillería, Procesos, $2^{\text {a }}$ Parte, Letra D, exp. 99, $f$. $15 r$. 
También queda plenamente confirmado su manera de actuar, como piloto y mercader, en la Sentencia condenatoria que contra él emitió la Real Audiencia:

... que lo tracte y modo de viure del dit Francisco Sasso és anar per la mar y marinejant y ha fet diversos viatges a diverses parts y senyaladament a Argel ... y en aquella ha tengut pràtica, tracte, conexences y familiaritats per lo molt temps e moltes vegades que és estat en aquella ${ }^{112}$.

Quiero recordar que su campo de acción comercial se desarrolló principalmente entre Argel y Valencia, y que los dos productos con los que más traficó fueron la cera y las pieles de toro, de los que trajo cantidades considerables que luego vendía en Valencia. Normalmente adelantaba dichos productos a artesanos como cereros, zapateros, marroquineros, etc. Posteriormente, al cabo del plazo convenido le pagaban lo estipulado ante su notario de siempre, el ya tantas veces citado Felipe Ayerbe. Sus actividades comerciales con Argel las tenemos documentadas desde 1534 a $1595^{113}$. De nuevo hay que lamentar la pérdida de los protocolos de Ayerbe, una verdadera cantera informativa de lo más rica y variada para la historia económica de Valencia y especialmente para la biografía de Francisco Sasso.

Además de comerciar con los géneros que ofrecía el mercado argelino, se dedicó, tal como aparecen en los Protocolos de dicho notario, a gestionar la liberación de cautivos, tanto en los viajes oficiales de los trinitarios como en expediciones organizadas por los mercaderes y otros particulares, tales como nobles y villas costeras que enviaban a Argel naves alquiladas para rescatar a sujetos de su jurisdicción caídos en cautividad, como hemos comentado ya anteriormente.

Especial interés reviste su relación con el padre Juan Gil y sus continuadores con los que se involucró con motivo de los viajes de redención que se celebraron entre 1580 y 1595 , los cuales tenían el puerto de Valencia como punto de partida hacia Argel. Él se encargaba de buscarles un barco, normalmente del tipo saetía, e igualmente en el contrato se especificaba que el sueldo del piloto debía correr a cargo de los redentores, y el nombramiento recaía sistemáticamente a favor de Francisco Sasso, como lo vemos confirmado una y otra vez en los Libros de la Redención y hemos comentado en su lugar correspondiente. Se convirtió así en el intermediario entre el padre Gil y los frailes que siguieron sus pasos en viajes sucesivos y los patrones de las saetías que alquilaban en sus viajes a Argel. De las seis redenciones de los trinitarios que llevaron a cabo en el siglo XVI, en tres de ellas tenemos constancia documental explícita de que fue Francisco Sasso quien pilotó la saetía de la redención. En otras dos es casi segura su participación, si bien nos falta la apoyatura documental por haberse perdido. Y en la última expedición, la de 1599 estaba ya retirado de la vida activa de piloto.

112. ARV: Real Cancillería, Procesos, $2^{\mathrm{a}}$ Parte, Letra D, exp. 99, f. 27r-30r.

113. De nuevo agradezco a Roberto Blanes los pormenores que me ha dado de la vida comercial de este mercader. 
En la redención de 1580, la primera que hizo el padre Juan Gil, fue cuando tomó contacto por primera vez con el fraile trinitario. En este primer viaje del padre Juan Gil fue en calidad de mercader, no de piloto de la saetía, como lo hará en los viajes sucesivos. Francisco Sasso conoció a Cervantes en Argel, con toda seguridad ya antes de este año de 1580, en viajes anteriores que hizo a dicha ciudad, pues nuestro escritor era muy conocido allí por los mercaderes valencianos, como sabemos por la Topografía e Historia General de Argel de Haedo, o mejor de Antonio de Sosa, a quien la crítica moderna da por ser el verdadero autor de la obra.

Por uno de los muchos pleitos que tuvo que afrontar en diversos tribunales de justicia: Consulado, Justicia Civil, Real Audiencia, etc., a los que comparecía a través de procuradores, cosa normal si pensamos en la envergadura de sus negocios, sabemos que vivía aún en 1601. Ello supone una edad avanzada para su época pero no improbable ni imposible. Se conocen muchos casos de personas que alcanzaron esa edad e incluso más alta. Él ya se habría retirado del pilotaje y los viajes por el mar y se limitaría a llevar la dirección de los negocios ayudado por familiares o empleados.

\section{CONCLUSIONES}

A lo largo de la comunicación se han puesto de relieve las novedades aportadas por la documentación exhumada últimamente en los archivos valencianos en relación con Cervantes, el padre Gil y los mercaderes valencianos que colaboraron con él en el rescate de cautivos. Si tenemos que destacar algunos aspectos a modo de conclusión del artículo podemos reseñar en primer lugar los contratos de las naves de redención, normalmente del tipo denominado saetías. Antes conocíamos sólo los nombres del patrón y de la embarcación; ahora conocemos los contratos notariales que se redactaron en el fletamento de las naves redentoras de los viajes de 1583 y de 1587-1588, cuyas estipulaciones pueden ser aplicadas al de 1580, cuyo protocolo se ha perdido.

Especialmente interesantes son los nuevos datos que aparecen en torno a la estancia de Cervantes en Valencia en noviembre de 1580 en compañía de dos de sus amigos que había conocido en Argel y su involuntaria e insospechada participación en unas sorprendentes apuestas que por aquellos días se empezaron a celebrar, justamente después que nuestro escritor certificase a su instigador principal, Miquel Tauler, de que Jeroni Planelles, a quien se daba por muerto en Valencia, en realidad seguía vivo y cautivo, en Argel.

Digno de destacarse son los datos novedosos que se aportan sobre la redención de 1583, pues se muestra palpablemente la interacción de los mercaderes valencianos con el padre Gil en el desarrollo de las gestiones del rescate: le acompañan a Argel en el barco alquilado por el trinitario, y allí están ellos con los dineros que traen de los familiares de cautivos, a los que el religioso se encarga de buscar, y si no son suficientes los dineros que traen de sus 
familiares allí están a su disposición los fondos de la limosna general para completarlos. Otras veces son los propios cautivos quienes se obligan a pagar su rescate a los mercaderes, una vez vueltos a Valencia y es entonces cuando éstos adelantan el precio del rescate. Además los mercaderes ayudaban al redentor a buscar la nave, a acompañarle en sus viajes hasta Alcoy y Cocentaina a comprar paños que después teñían en Valencia y vendían en Argel. Este mutuo apoyo siguieron practicándolo cuando desapareció el padre Gil de la dirección de la empresa redentora y vinieron otros religiosos a ocupar su lugar.

Entre estos mercaderes destaca la presencia de dos de ellos, Juan Estéfano y Francisco Sasso, de los que hemos diseñado una biografía bastante extensa. Aunque no eran valencianos de naturaleza estuvieron asentados aquí durante muchos años, y tuvieron además una especial relación no sólo con el padre Gil sino también con Cervantes, especialmente el primero. De los otros mercaderes valencianos, que conocemos por otros documentos, no hemos hallado novedades dignas de mención y por eso no hablamos de ellos.

Para terminar es preciso hablar de la importancia de los protocolos de Felipe Ayerbe, pues por su oficina pasaban muchos mercaderes y maestros de gremios y acaparaba en gran medida la escrituración de los tratos que se hacían antes y después de los rescates de los cautivos cristianos. Era el notario ante el que acudía el padre Gil para contratar los barcos y Estéfano y Sasso para firmar todos sus negocios mercantiles y asuntos personales. Sin apenas riesgo de equivocarnos podemos asegurar que allí acudió Cervantes para saldar sus deudas con los mercaderes una vez regresado de Argel. Y por eso es más de lamentar que justamente se haya perdido el protocolo de dicho notario y del año $1580^{114}$.

\section{APÉNDICE DOCUMENTAL}

1.

1581, mayo, 18. Valencia.

Joan Baptista Figueres, en una alegación que presentó en la Real Audiencia, asegura que Cervantes y don Diego de Benavides llegaron a Valencia desde Argel en torno a la fiesta de Todos los Santos (1 de noviembre de 1580), y que Miquel Tauler supo de su boca que Jeroni Planelles estaba vivo y se hallaba cautivo en Argel.

ARV: REAL AUDIENCIA, Procesos, 2a Parte, Letra M, exp. 651, f. 9rv.

114. Felipe Ayerbe estuvo trabajando como notario de la ciudad de Valencia durante unos treinta años, desde 1568 que empezó a ejercer la profesión hasta un momento avanzado de la última década del siglo XVI, en que falleció. Hay que lamentar por ello la pérdida de unos treinta volúmenes de protocolos que conformaban su colección. Sólo se conservan dos protocolos suyos, los de 1583 y 1587, pues los otros tres que figuran a su nombre en el Catálogo de Protocolos del ARV corresponden a su hijo, también notario y del mismo nombre, y correspondientes al siglo XVII. 
VII.- Item, e dix que noresmenys en la festa de Tots Sancts pròxime pasada o poch abans, arribaren també a la present ciutat dos catius crestians, los quals eren del regne de Castella, lo hu dels quals se deya SERVANTES y l'altre DON DIEGO [de BENAVIDES], los quals també públicament digueren y testificaren com en la çiutat de Alger, terra de infels, restava viu lo dit Hierony Planelles y açò u entengué lo dit Taulell, part contrària, dels dits catius crestians y se'n certificà de aquells ${ }^{115}$.

VIII.- Item, diu ut supra, que lo dit Miquel Taulell ${ }^{116}$ en la dita festa de Tots Sancts pròxime pasada, ans y aprés, axí per lo que entengué del dit Joan Matos, patró, com encara dels dits SERVANTES y de DON DIEGO [DE BENAVIDES] y de altres persones ja sabia y tenia entés com lo dit Hierony Planelles era viu y estava catiu en Alger ${ }^{117}$.

1581, mayo, 18. Valencia.

El mismo día Miquel Tauler responde a las alegaciones de Joan Baptista Figueres y da otra versión de los hechos. Soslaya su entrevista con Cervantes y se remite a la opinión de la gente que según él opinaba que el Jeroni Planelles cautivo en Argel, no era valenciano, sino otro que llevaba el mismo nombre y era natural de Alicante.

ARV: REAL AUDIENCIA, Procesos, 2a Parte, Letra M, exp. 651, f. 12r.

VII.- Item, e dix que nega lo dit capítol, bé que sentí a dir per la present ciutat, ell responent, que los dits catius deyen que en dita ciutat de Alger y havia un Hieroni Planelles, emperò que no sabien si era valencià y dient-ho, ell responent, a d'algunes persones en Lonja deyen que lo dit Planelles que estava en Alger no era lo de València sinò que era un Planelles de Alacant ${ }^{118}$.

115. VII.- "Item, dijo además que en la última fiesta de Todos los Santos o poco antes, llegaron también a la presente ciudad dos cautivos cristianos, naturales del reino de Castilla, el uno de los cuales se llamaba CERVANTES y el otro DON DIEGO [DE BENAVIDES], los cuales también dijeron y testificaron públicamente que en ciudad de Argel, tierra de infieles, se encontraba vivo dicho Jeroni Planelles, y así lo supo el dicho Tauler, parte contraria, de boca de dichos cautivos cristianos y se aseguró de ellos".

116. Sabemos por otras muchísimas escrituras que en realidad se apellidaba Tauler.

117. VIII.- "Item, dice como arriba, que el dicho Miquel Tauler en la dicha última fiesta de Todos los Santos, antes y después, así por lo que oyó de dicho Joan Matos, patrón de nave, como también de CERVANTES y de DON DIEGO [DE BENAVIDES] y de otras personas ya sabía y tenía por cierto que dicho Jeroni Planelles estaba cautivo en Argel".

118. VII.- "Item, niega lo que se dice en dicho capítulo, que oyó decir por la presente ciudad, el que responde, que dichos cautivos aseguraban que en dicha ciudad de Algel se hallaba un Jeroni Planelles, pero que no sabían si era valenciano y diciendo esto, el que responde, a algunas personas en la Lonja, decían que el Planelles que se hallaba en Argel no era el de Valencia sino un Planelles de Alicante". 
1581, mayo, 18. Valencia.

Bertomeu Navarro testifica en un interrogatorio que vio personalmente a Miquel Tauler ir a «hablar y conversar» con MIGUEL DE CERVANTES.

ARV: REAL AUDIENCIA, Procesos, $2^{\text {a }}$ Parte, Letra M, exp. 651, f. 22r.

VII.- Item, e dix que té per ver lo dit capítol per ço què, ell testimoni, veu al dit Tauler anar parlar e conversar ab lo dit SERVANTES y així creu aquell el digué y el certificà del contengut en dit capítol ${ }^{119}$.

4.

1583, mayo, 14. Valencia.

Carta de fletamento. Francisco Pau, vecino de Vinaroz, arrienda la nave de su propiedad «Virgen de la Misericordia y San Telmo», fondeada en el puerto de Valencia, al trinitario fray Juan Gil, redentor de cautivos de la Provincia de Castilla, para el viaje que estaba preparando para liberar a cautivos cristianos detenidos en Argel.

ARV: PROTOCOLOS, 154, ff. 214r-218v (Notario: Felipe Ayerbe)

\section{// Die XIIII madii anno a Nativitate Domini M D LXXXIII //}

Sepan cuantos esta carta de fletamento vieren cómo yo, Francisco Pau, vecino de la villa de Vinarós, estante al presente en esta ciudad de Valencia, patrón que soy después de nuestro señor Dios, de la nave nombrada La Virgen María de la Misericordia y San Telmo, surta al presente en la playa de esta ciudad de Valencia, por el tenor de esta pública carta de mi buen grado y cierta ciencia, digo que fleto e por título de fletamento libro a vos, el muy reverendo Padre Fray Juan Gil, fraile del Orden de la Santísima Trinidad, redentor de cautivos cristianos nombrado por Su Majestad, estante al presente en esta dicha ciudad de Valencia que al otorgamiento de esta carta estáis presente y aceptante de dicha mi nave, bien amarinada y exarciada y bien estanca de cubierta, quilla y costado, apta y suficiente para el viaje abajo escrito, así que prometo y me obligo recibir en aquella de vos, dicho Padre Fray Joan Gil o de quien por vos fuere y de quien vos quisiereis en la playa del lugar del Grao de dicha ciudad de Valencia, todas las ropas, mercaderías e cosas que me daréis hasta tener el suficiente cargo que podrá llevar dicha mi nave; recibido que haya el cual cargo luego partiré de dicha playa y haré vela con dicha mi nave e iré derecha vía viaje no mudando ni tiempo perdiendo, siguiendo el orden del piloto que por vos me será dado para dicho viaje hasta haber llegado a la ciudad de Alger, en donde entregaré el dicho cargo conforme se me ordenará por las pólizas

119. VII.- "Item, dijo que tiene por cierto lo que se dice en dicho capítulo, por cuanto, el testigo, vio a dicho Tauler ir a hablar y conversar con dicho CERVANTES, y por ello cree que aquel le dijo y le certificó lo que se contiene en dicho capítulo". 
de cargazón; y después en dicha ciudad de Argel me detendré con dicha mi nave por el tiempo que vos o la persona que por vos fuere quisiereis, donde recibiré así mismo en dicha mi nave de vos, dicho Fray Juan Gil o de quien por vos allí será y de quien quisiereis las ropas, mercaderías y cosas que me daréis hasta tener el suficiente cargo para dicha mi nave; recibido que haya el cual cargo luego partiré de dicha ciudad de Argel y haré vela con dicha mi nave y me vendré viaje no mudando ni tiempo perdiendo, siguiendo así mismo el orden del piloto que por vos me será dado para dicho viaje, hasta haber vuelto y llegado a la dicha playa del dicho lugar del Grao de Valencia donde entregaré dicho cargo, conforme se me ordenará por las pólizas de cargazón.

$\mathrm{E}$ yo, dicho patrón, prometo y me obligo tener dicha nave a punto $\mathrm{y}$ aparejada para recibir el dicho cargo para los diez días del mes de junio que primero vendrá de este presente año en la playa del dicho lugar del Grao de la mar de esta ciudad de Valencia. Dándome y pagándome de fletes a razón de ciento y siete libras moneda valenciana por cada un mes mientras estuviere dicha nave en hacer dicho viaje de ida, estada y vuelta, comenzando a correr y ganar dichos fletes y sueldo la dicha nave, de dicho día de diez de junio que primero vendrá en adelante, y si antes empezare a recibir en dicha nave el dicho cargo, dichos fletes se empiecen a contar de aquel día en adelante, los cuales fletes y sueldo hayan de correr y corran. E dicha nave haya de ganar y gane continuamente hasta tanto que yo, dicho patrón, sea enteramente pagado de dichos fletes, de tal manera que después de haber vuelto a esta ciudad de Valencia y haber librado el cargo que traerá dicha nave, no pagándome dichos fletes siempre corra dicho sueldo a dicha razón de ciento y siete libras por cada un mes, hasta tanto y hasta el día que sea yo pagado por entero de dichos fletes. $\mathrm{Y}$ es pacto y condición que yo, dicho patrón, sea obligado cobrar dichos fletes y sueldo así en la ciudad de Argel como en esta ciudad de Valencia de las personas que vos, dicho Padre Fray Juan Gil diréis y me diereis por memoria para cobrar.

E otrosí, es pacto y condición que me hayáis de dar y pagar en el modo y manera que bajo se dirá doscientas y catorce libras de dicha moneda valenciana por los fletes de dos meses, no embargante dicha nave haga dicho viaje a dicha ciudad de Alger y de vuelta hasta la presente ciudad de Valencia en menos tiempo de dos meses; y si más de dos meses se detuviere dicha nave en hacer dicho viaje me hayáis de pagar los fletes al mismo respecto por todo el tiempo que más se detuviere. El modo de la paga de dichos fletes ha de ser, es a saber, que antes de partir dicha nave de la playa de esta ciudad de Valencia para ir a Alger me hayáis de dar y pagar ciento y siete libras de dicha moneda por los fletes de un mes y otras ciento y siete libras en la dicha ciudad de Argel, como es de costumbre entre patrón y mercader en moneda de Argel por los fletes de otro mes, y si más se me debiere de fletes me lo hayáis de pagar al respecto en esta ciudad de Valencia, los cuales fletes como dicho es, yo haya de cobrar de las personas que me diereis por memoria para cobrar; y en caso que para los diez días del mes de junio que primero vendrá de este año no tuviere dicha mi nave aparejada y cual conviene para recibir 
dicho cargo y hacer el dicho viaje en la dicha playa del dicho lugar del Grao de esta ciudad de Valencia, donde al presente está surta, pasado dicho día quiero esté en facultad vuestra podáis fletar si quisiereis, otro cualquier navío que a vos bien os pareciere para hacer dicho viaje y por el precio y fletes que bien visto os fuere, en el cual caso prometo y me obligo de vos dar y pagar todos los maravedís y cantidad de dinero que más huviereis de pagar de fletes al navío que fletareis que no a mi si hubiera hecho el dicho viaje, es a saber, pagaros todo el daño que por dicha razón se vos recreciere. Y así mismo es pacto y condición que de ida a dicha ciudad de Argel y de vuelta a esta ciudad de Valencia, yo el dicho patrón, pueda llevar en dicha nave ropa terciada hasta suma de cien libras moneda valenciana, con que dicha ropa haya de ser de dineros míos y marineros de dicha nave; y en caso que yo tomare y llevare en dicha nave ropa alguna de persona otra alguna sin vuestra licencia, sino fuere la susodicha, quiero que dicha ropa sea perdida y el precio de aquella quiero la convirtáis en rescatar cautivos cristianos. $\mathrm{Y}$ es pacto y condición que vos, dicho padre Fray Juan Gil, me hayáis de dar piloto para hacer el presente viaje y pagarle el sueldo que se le debiere, y así mismo seáis obligado pagarme todas las averías y derechos que yo dicho patrón hubiere de pagar en dicha ciudad de Argel que toquen a pagar a dicha nave. E si se siguiere que estando dicha nave cargada en la playa de dicha ciudad de Argel para volver a esta ciudad de Valencia, el rey de Argel la embargare por causa vuestra, en tal caso vos, dicho Padre Fray Juan Gil, seáis obligado a hacer la costa a mí, dicho patrón, y a los marineros de dicha nave por todo el tiempo que durare dicho embargo.

E yo, dicho Fray Juan Gil, redentor de cautivos cristianos nombrado por Su Majestad, como dicho es, presente y aceptante el dicho fletamento sí e según y de la manera que por vos, el dicho patrón va declarado, prometo y me obligo a vos, el dicho patrón, de entregaros el dicho cargo y de pagaros los dichos fletes y hacer todo lo demás que a mí toca, sí e según que arriba va declarado.

E para mayor seguridad y cumplimiento de lo contenido en esta escritura, nosotros las dichas partes, prometemos y nos obligamos, a saber es, la una parte a la otra e la otra a la otra ad invicem et vicisim de efectuar y cumplir todo lo que a cada una de nosotras dichas partes toca y se esguarda haber de efectuar y cumplir y de no contravenir en manera alguna a lo contenido en esta escritura so pena de doscientas libras de dicha moneda valenciana, pagadoras por la parte que contraviniere a la parte que obedeciere, por pena y en nombre de pena, danyo e interesse. Para atender y cumplir todo lo cual obligamos la una parte a la otra e la otra a la otra ad invicem et vicisim, a saber es, yo el dicho patrón, la dicha mi nave, fletes y lo mejor parado de ello e mis bienes; e yo, el dicho Fray Juan Gil, todos mis bienes muebles e raíces, habidos e por haber, doquier que sean. En firmeza de lo cual otorgamos esta carta por ante el escribano público y testigos deyuso escritos.

Que fue fecha y otorgada en la ciudad de Valencia a los catorce días del mes de mayo, año del Nacimiento de nuestro Salvador Jesucristo de mil y quinientos y ochenta y tres años. 
Testigos que fueron presentes a todo lo que dicho es: Joan de Estéfano y Andrea de Trentig, mercaderes raguceos, estantes al presente en esta ciudad de Valencia.

1583, junio, 16. Grao de Valencia.

Auto de salida para Argel de la nave Ntra. Sra. de Misericordia y San Telmo, firmada por el P. Juan Gil, y Francisco Sasso y Juan Estéfano como testigos.

AHN : CLERO, Códices, núm. 119, f. 81r. (Libro de la Redención de la Orden de la Trinidad de 1583)

[Al margen]: Auto de la partida para Argel.

En la playa del mar del Grao de Valencia, a diez y seis días del mes de junio de dicho año, por la mañana, al punto que amanecía, su Paternidad Padre fray Juan Gil y fray José Fornario y yo el presente escribano embarcamos en el navío de Francisco de Pao, vecino de Vinarós, que se nombra la nave «Nuestra Señora de Misericordia y San Telmo», para ir a la ciudad de Argel y se alzaron las velas a la dicha hora y partimos el dicho día, navegando en la mar adelante, de que doy fe.

Siendo testigos: FRANCISCO SASSO y JUAN ESTÉFANO, vecinos de Valencia

FRAY JUAN GIL Ante mí: Juan Martínez.

6.

1583, julio, 7. Valencia

El P. Juan Gil recibe 500 escudos de oro de manos de Francisco Sasso y de Juan Estéfano, mercaderes de Valencia, para el rescate de Don Jerónimo de Palafox.

AHN: CLERO, Códices, 119, f. 37r. (Libro de la Redención de la Orden de la Trinidad)

En la ciudad de Argel, a siete días del mes de julio de 1583 años por ante mí Juan Martínez, escribano susodicho, el muy Reverendo P. fray Juan Gil, recibió de Francisco Sasso y Juan Estéfano, mercaderes, vecinos de Valencia, quinientos escudos de oro para ayuda al rescate de Don Jerónimo de Palafox, natural de Ariza, que son doblas mil seiscientas e veinte, que valen trescientas y cuarenta y cuatro mil y doscientos y cincuenta maravedís. 


\section{BIBLIOGRAFÍA CITADA}

Astrana Marín, Luis (1948-1958). Vida ejemplar y heroica de Miguel de Cervantes Saavedra. Madrid: Ed. Reus. 7 vols.

Benítez, Rafael (2008). «La tramitación del pago de rescates a través del Reino de Valencia. El último plazo del rescate de Cervantes», en Le commerce des captifs. Les intermédiares dans l'échange et le rachat des prisonniers en Méditerranée, XVIe-XVIIIe siècle. Wofgang Kaiser (ed.). Roma: École Française de Rome, pp. 193-217.

Bennassar; Bartolomé (1989). Los cristianos de Alá: la fascinante aventura de los renegados. Madrid: Nerea.

Braudel, Fernand (1976). El Mediterráneo y el mundo mediterráneo en la época de Felipe II. México: Fondo Cultura Económica. 2 vols.;

Bunes Ibarra, Miguel Ángel de (1989). La imagen de los musulmanes y del norte de África en la España de los siglos XVI y XVII. Madrid: CSIC.

Camamis, George (1977). Estudios sobre el cautiverio en el Siglo de Oro. Gredos.

Canavaggio, Jean (1997). Cervantes. Madrid: Espasa Calpe;

Cervantes, Miguel de (2004). Los trabajos de Persiles y Sigismunda. Carlos Romero Muñoz (ed.) Madrid: Cátedra.

Garcés, María Antonia (2005). Cervantes en Argel. Madrid: Gredos.

García Arenal, Mercedes y Bunes Ibarra, Miguel Ángel de (1992). Los españoles en el norte de Africa: Siglos XV-XVIII. Madrid: Mapfre.

Haedo, Diego de [Antonio de Sosa] (1927-1929). Topografia e Historia General de Argel. Madrid: Sociedad de Bibliófilos Españoles. 3 vols.

Martínez Torres, José A. (2004). Prisioneros de los infieles. Vida y rescate de los cautivos cristianos en el Mediterráneo musulmán (Siglos XVI-XVII). Barcelona: Ed. Bellaterra.

Pérez Pastor, Cristóbal (1897). Documentos cervantinos hasta ahora inéditos recogidos y anotados por el presbitero... Madrid. Establecimiento Tipográfico de Fortanet.

Porres, Bonifacio (1997-1998). Libertad a los Cautivos. Actividad redentora de la orden trinitaria, Córdoba-Salamanca, Secretario Trinitario, 3 vols.

Sanchis Sivera, José (1915). La Iglesia parroquial de Santo Tomás de Valencia. Valencia: Vives Mora.

Sliwa, Krzystov (1999). Documentos de Miguel de Cervantes Saavedra. Pamplona: Ed. Universidad de Navarra.

Solá, Emilio (1995). Cervantes y la Berbería. México: Fondo de Cultura Económica.

Solá, Emilio (1988). Un Mediterráneo de piratas: Corsarios, renegados y cautivos. Madrid: Tecnos.

Velasco, Santos (1872). «Documento sobre el rescate de Cervantes», Revista de Archivos Bibliotecas y Museos, II (5), pp. 1-8.

Recibido: 7 de marzo de 2016

Aceptado: 3 de junio de 2016 